University of South Florida

DIGITAL COMMONS Digital Commons @ University of @ UNIVERSITY OF SOUTH FLORIDA South Florida

$1-1-2008$

\title{
Exploration of a Shift in Household Transportation Spending from Vehicles to Public Transportation
}

CUTR

Follow this and additional works at: https://digitalcommons.usf.edu/cutr_nctr

\section{Recommended Citation}

"Exploration of a Shift in Household Transportation Spending from Vehicles to Public Transportation," National Center for Transit Research (NCTR) Report No. CUTR-NCTR-RR-2007-05, Center for Urban Transportation Research, University of South Florida, 2008.

DOI: https://doi.org/10.5038/CUTR-NCTR-RR-2007-05

Available at: https://scholarcommons.usf.edu/cutr_nctr/165

This Technical Report is brought to you for free and open access by the National Center for Transit Research (NCTR) Archive (2000-2020) at Digital Commons @ University of South Florida. It has been accepted for inclusion in Research Reports by an authorized administrator of Digital Commons @ University of South Florida. For more information, please contact digitalcommons@usf.edu. 


\title{
Exploration of a Shift in Household Transportation Spending from Vehicles to Public Transportation
}

National Center Transit Resear

\author{
Center for Urban \\ Transportation Research \\ University of South Florida, Tampa \\ January 2008
}

National Center for Transit Research

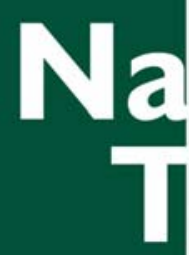

BD 549-43

National Center for Transit Research

Center for Urban Transportation Research University of South Florida

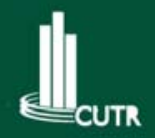




\section{Exploration of a Shift in Household Transportation Spending from Vehicles to Public Transportation}

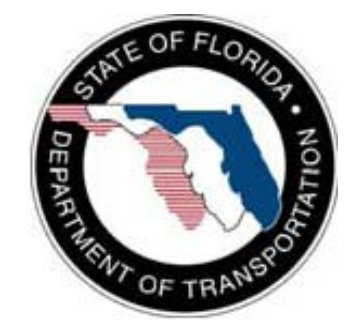

State of Florida Department of Transportation

Public Transit Office

605 Suwannee Street

Tallahassee, FL 32399-0450

(850) 414-4500

Project Manager: Tara Bartee
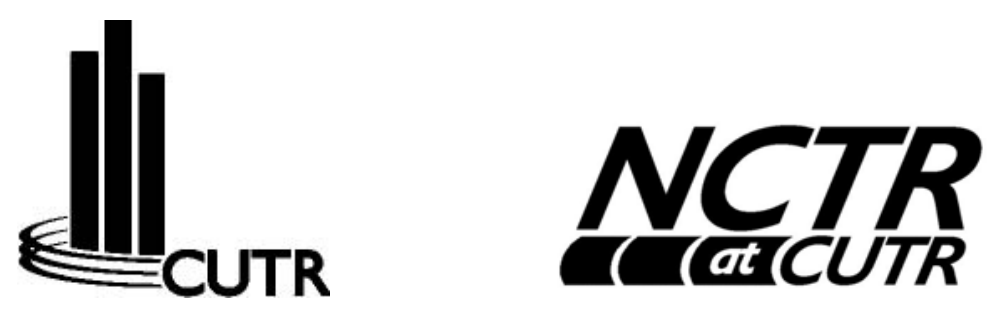

National Center for Transit Research

Center for Urban Transportation Research

University of South Florida

4202 E. Fowler Avenue CUT100

Tampa, FL 33620-5375

(813) $974-3120$

Principal Investigators: $\quad$ Steven Polzin, Director of Public Transportation Research Program

Project Staff:

Xuehao Chu, Senior Research Associate

Vishaka Shiva Raman, Graduate Research Assistant

The opinions, findings, and conclusions expressed in this publication are those of the authors and not necessarily those of the State of Florida Department of Transportation. 


\begin{tabular}{|c|c|c|c|c|}
\hline $\begin{array}{l}\text { 1. Report No. } \\
\text { NCTR } 77722, \text { FDOT BD- } \\
549-43\end{array}$ & \multicolumn{2}{|c|}{ 2. Government Accession No. } & \multicolumn{2}{|c|}{ 3. Recipient's Catalog No. } \\
\hline \multirow{2}{*}{\multicolumn{3}{|c|}{$\begin{array}{l}\text { 4. Title and Subtitle } \\
\text { Exploration of a Shift in Household Transportation } \\
\text { Spending from Vehicles to Public Transportation }\end{array}$}} & \multicolumn{2}{|l|}{$\begin{array}{l}\text { 5. Report Date } \\
\text { January } 2008\end{array}$} \\
\hline & & & \multicolumn{2}{|c|}{ 6. Performing Organization Code } \\
\hline \multicolumn{3}{|c|}{$\begin{array}{l}\text { 7. Author(s) } \\
\text { Steven E. Polzin, Xuehao Chu, Vishaka Shiva Raman }\end{array}$} & \multicolumn{2}{|c|}{ 8. Performing Organization Report No. } \\
\hline \multicolumn{3}{|c|}{ 9. Performing Organization Name and Address } & \multicolumn{2}{|c|}{ 10. Work Unit No. (TRAIS) } \\
\hline \multicolumn{3}{|c|}{ Center for Urban Transportation Research } & \multicolumn{2}{|c|}{$\begin{array}{l}\text { 11. Contract or Grant No. } \\
\text { BD 549-43 }\end{array}$} \\
\hline \multirow{2}{*}{\multicolumn{3}{|c|}{$\begin{array}{l}\text { 12. Sponsoring Agency Name and Address } \\
\text { Florida Department of Transportation } \\
605 \text { Suwannee St. MS } 30 \\
\text { Tallahassee, Florida } 32399\end{array}$}} & \multicolumn{2}{|c|}{$\begin{array}{l}\text { 13. Type of Report and Period Covered } \\
\text { Final Report }\end{array}$} \\
\hline & & & \multicolumn{2}{|c|}{ 14. Sponsoring Agency Code } \\
\hline \multicolumn{5}{|c|}{$\begin{array}{l}\text { 15. Supplementary Notes } \\
\text { Prepared in cooperation with the FDOT }\end{array}$} \\
\hline \multicolumn{5}{|c|}{$\begin{array}{l}\text { Despite continued and growing public support of public transit, traffic congestion continues to get worse and } \\
\text { transit ridership and service levels have grown but not sufficiently to play a more meaningful role in addressing } \\
\text { growing travel demands. As a result, interest continues in exploring how significant service increases might } \\
\text { provide adequate transit capacity and sufficiently attractive service levels to attract enough ridership to offset } \\
\text { the need of households for the current number of vehicles. Similarly, policy analysts speculate that the } \\
\text { resources saved by households with fewer autos may represent a sufficient consumer benefit to justify or } \\
\text { offset the higher subsidy costs necessary to provide the enhanced services. While speculation on this topic is } \\
\text { common amongst transit planners and advocates, the literature currently offers little insight into this issue. }\end{array}$} \\
\hline \multicolumn{5}{|c|}{$\begin{array}{l}\text { This report estimates the average costs of private car ownership in the country based on the household } \\
\text { income and expenditures using the Bureau of Labor Statistics (BLS) data. Travel behavior as a function of } \\
\text { vehicle ownership is explored with the National Household Travel Survey (NHTS). Analysis of the datasets is } \\
\text { used to develop a better understanding of the economic and travel implications potentially arising as a result of } \\
\text { households reducing their automobile ownership. As part of the study, a scenario analysis was developed } \\
\text { using an Excel spreadsheet tool. This tool can be used by analysts to evaluate probable consequences of } \\
\text { reduced vehicle ownership. The analysis is driven by utilizing relationships between travel behavior, } \\
\text { transportation spending and household vehicle availability. The research offers several observations } \\
\text { regarding the magnitude of the behavior changes that might be expected with lower vehicle ownership as well } \\
\text { as the capacity and cost of transit expansion required to accommodate the demands. }\end{array}$} \\
\hline \multicolumn{2}{|c|}{$\begin{array}{l}\text { 17. Key Word } \\
\text { vehicle ownership, National Household Travel } \\
\text { Survey, public transportation, ridership, vehicle } \\
\text { reduction, vehicle ownership costs }\end{array}$} & \multicolumn{3}{|c|}{$\begin{array}{l}\text { 18. Distribution Statement } \\
\text { No Restriction } \\
\text { This report is available to the public } \\
\text { through the NTIS, Springfield, VA } \\
22161\end{array}$} \\
\hline $\begin{array}{l}\text { 19. Security Classif. (of this report) } \\
\text { Unclassified }\end{array}$ & $\begin{array}{l}\text { 20. Security Cla } \\
\text { Unclassifiec }\end{array}$ & & $\begin{array}{c}\text { 21. No. of Pages } \\
63\end{array}$ & $\begin{array}{l}\text { 22. Price } \\
\text { No cost }\end{array}$ \\
\hline
\end{tabular}




\section{EXECUTIVE SUMMARY}

Despite continued and growing public support of public transit, traffic congestion continues to get worse and transit ridership and service levels have grown but not sufficiently to play a more meaningful role in addressing growing travel demands. As a result, interest continues in exploring how significant service increases might provide adequate transit capacity and sufficiently attractive service levels to attract enough ridership to offset the need of households for the current number of vehicles. Similarly, policy analysts speculate that the resources saved by households with fewer autos may represent a sufficient consumer benefit to justify or offset the higher subsidy costs necessary to provide the enhanced services. While speculation on this topic is common amongst transit planners and advocates, the literature currently offers little insight into this issue.

This report estimates the average costs of private car ownership in the country based on the household income and expenditures using the Bureau of Labor Statistics (BLS) data. Travel behavior as a function of vehicle ownership is explored with the National Household Travel Survey (NHTS). Analysis of the datasets is used to develop a better understanding of the economic and travel implications potentially arising as a result of households reducing their automobile ownership. As part of the study, a scenario analysis was developed using an Excel spreadsheet tool. This tool can be used by analysts to evaluate probable consequences of reduced vehicle ownership. The analysis is driven by utilizing relationships between travel behavior, transportation spending and household vehicle availability.

This effort looks more closely at empirically derived household spending as a function of the number of vehicles in the household. Literature typically cites average costs, often for new vehicles, and implies this represents the potential savings from household vehicle reductions. In reality, the marginal or incremental cost per incremental household vehicle appears to be well below numbers frequently seen in the literature purporting to be average vehicle ownership cost. The realizable household savings from relinquishing vehicles is more correctly reflected by using the marginal vehicle ownership cost. Interestingly, zerocar households do have vehicle expenditures as might be expected as these households may be renting vehicles occasionally, maintaining their license, or paying for gas, tolls, or parking when they ride with others. 
The consumer expenditure survey data indicate an average household savings of approximately $\$ 3,500$ would be realized for each reduced vehicle. The actual mean savings varies significantly across household types and is actually highest in instances where households have more vehicles than adults. Depending upon the nature of the policy initiative, lower income households with very low auto ownership costs may choose to relinquish a vehicle that produces a modest economic savings. Alternatively, higher income households with extra discretionary vehicles may relinquish a vehicle that produces significant economic savings but virtually no impact on travel behavior. Households with surplus vehicles are more likely to be in a position where they are able to reduce vehicle ownership and less likely to be in a position where this change in household fleet would influence travel behavior.

The travel behavior data suggest that there is a very significant difference in probable impact on transit use depending on which households relinquish vehicles. Huge shares of the transit increase associated with relinquishing vehicles can be attributed to households shifting from one to zero vehicles. Based on NHTS data, if there was a uniform reduction in vehicle ownership across household categories 88 percent of the increase in transit travel would be attributable to households moving to zero vehicle status. Clearly, existing travel behavior data indicate policies targeting vehicle reduction with the hope of increased transit use will require the creation of more zero-vehicle households or changes in behavior such that multi-adult households with vehicle shortages began shifting meaningful amounts of travel to public transportation - more so than is typically the case today for comparable households with different levels of vehicle availability.

This research suggests that a significant share of the household vehicle ownership savings would need to be captured in some form to support the incremental cost of providing additional transit service even though only modest shares of diverted travel would be captured by public transportation. The average unit subsidy per public transit trip in the US, net of fares but inclusive of the cost of providing supportive capital, is such that it would be likely to require 50 percent or more of the household vehicle relinquishing savings in some manner redirected to support public transportation services. This actual relationship would be influenced highly by the extent to which vehicle relinquishing resulted in higher transit ridership of the type modeled in the scenarios that assumed uniform reductions in vehicle 
ownership across all ownership categories. On the other hand, if a vehicle reductions strategy resulted in vehicle relinquishing primarily for multi-vehicle households, they would create far lower additional transit demand and hence the necessary additional service could be supported by a far lower share of the relinquished vehicles savings being redirected to transit subsidy.

The spreadsheet tool developed as part of this research provides a very convenient mechanism for evaluating scenarios of vehicle reduction and assessing the financial and travel implications. The tool is easy to use and sufficiently transparent that an analyst could test a variety of scenarios, alter numerous assumptions or even the behavioral database to see what the implications are. The spreadsheet is readily available for anyone to use or modify should they be interested in exploring this issue in their context or for follow-up research.

Occasionally, policy analysts assume an ability to capture household savings associated with vehicle relinquishing and subsequently use these resources to support public transportation. The reality is that such an initiative would likely cause huge equity implications. Consequently, new revenue sources to support public transportation would most likely be applied far more uniformly across the entire population whether or not the individuals relinquished a vehicle or directly benefited from the expanded transit service. Thus, the ability to couple transit service expansion initiatives with policies to encourage vehicle ownership reductions might be more difficult than implied.

Service supply enhancements are unlikely to be sufficient alone to induce sufficient additional ridership to enable lower vehicle ownership levels based on the transit service elasticity that exists today and the cost structure for public transit that exists today. The findings indicate that the transit impact of vehicle ownership reductions is currently highly dependent on increasing zero-vehicle households. Growing zero vehicle households would be expected to have a meaningful impact on transit use but this would also require a very significant additional investment in transit that is significant in the context of the total households savings from vehicle relinquishing. Thus, the most promising initiatives are likely to be those that use a variety of incentives for transit use and disincentives for auto ownership/use in locations where transit service can be provided efficiently. 


\section{TABLE OF CONTENTS}

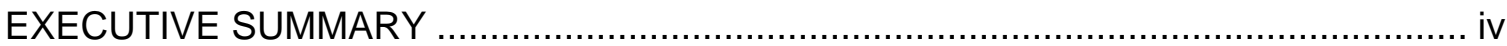

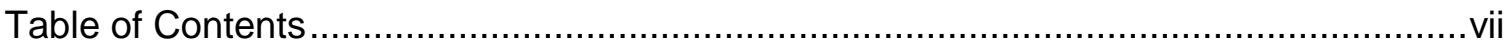

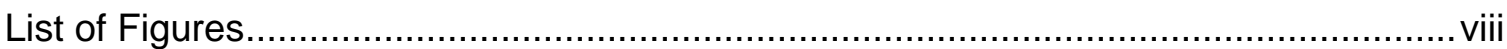

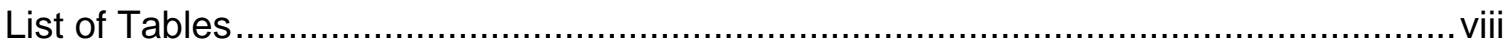

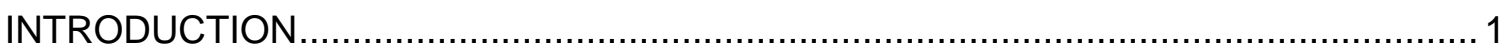

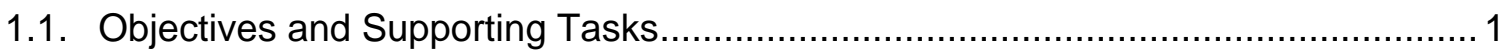

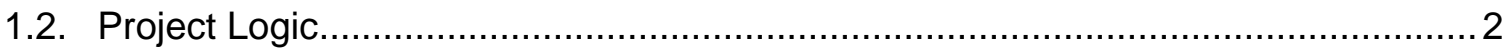

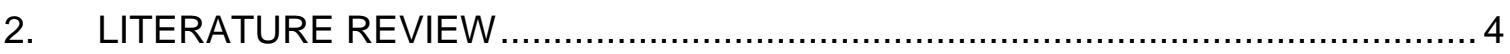

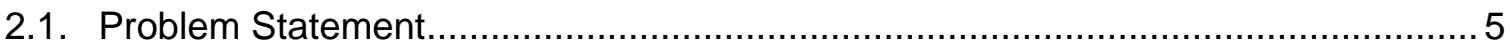

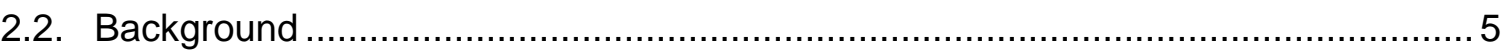

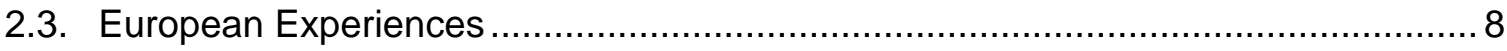

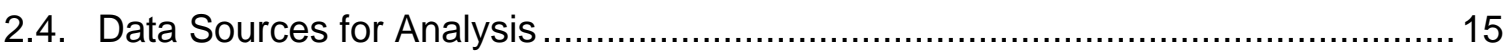

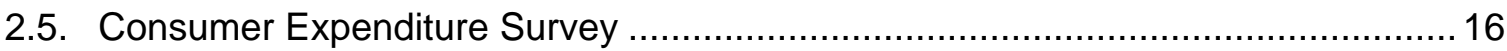

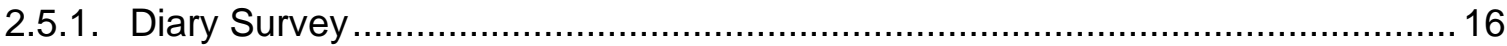

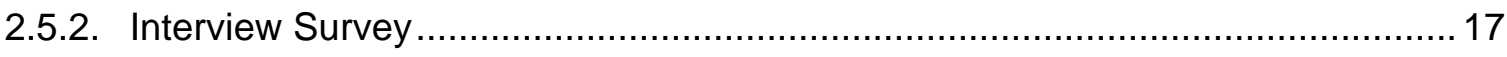

2.5.3. Cooperation Levels/Sample Numbers .................................................... 17

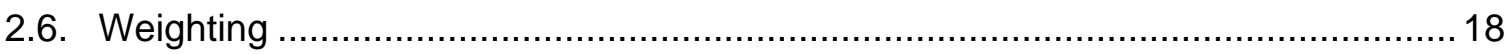

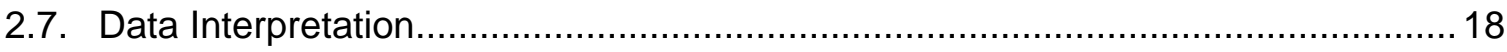

3. AVERAGE AND MARGINAL COSTS OF AUTO OWNERSHIP ........................ 19

3.1. Average Costs ........................................................................................ 19

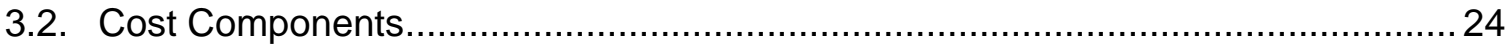

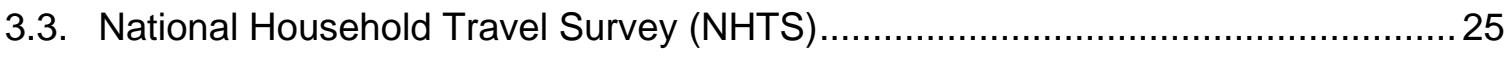

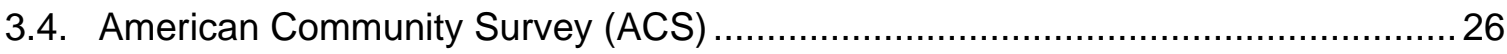

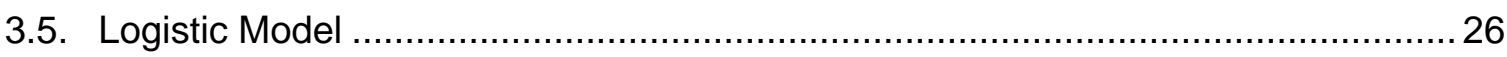

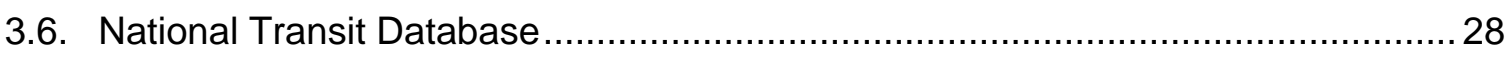

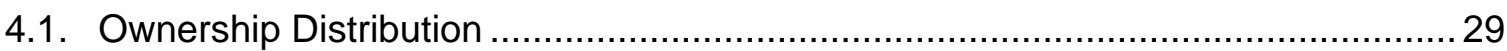

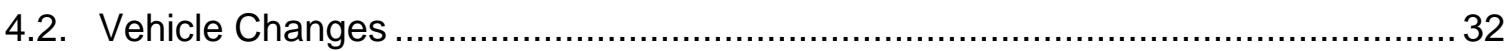

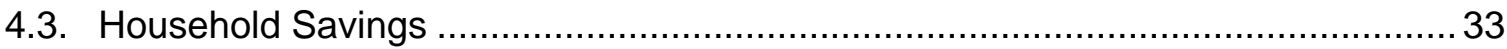

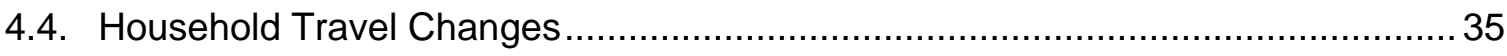

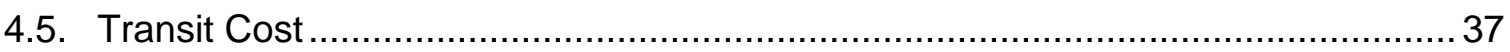

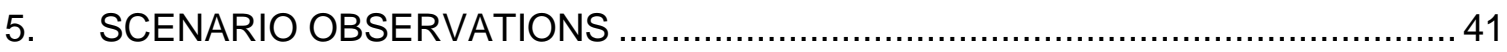

5.1. Overall Observations and Conclusions ................................................... 49

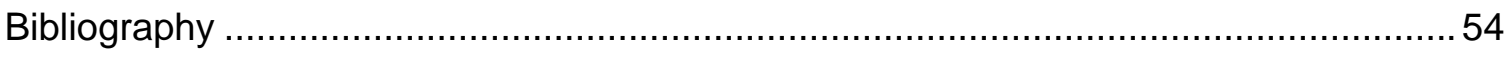




\section{LIST OF FIGURES}

Figure 1 Analysis of the Potential Impacts of Reduced Vehicle Ownership.......................... 3

Figure 2 NTS Household Car Availability by Area ........................................................ 10

Figure 3 Transportation as a Percent of Household Expenditures in Europe .....................10

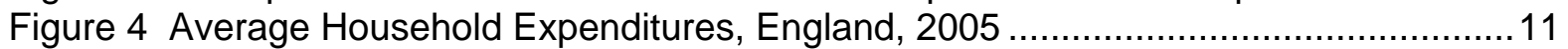

Figure 5 Average Household Expenditure for US, 2005 ......................................... 13

Figure 6 Household Transportation Spending by Category for US and UK ......................13

Figure 7 Comparison of Housing and Transportation Expenditure for UK and US .............15

Figure 8 Average Cost of Owning and Operating Private Automobiles ............................22

Figure 9 Transportation Expenditures, 1992-2005 ..................................................... 23

Figure 10 Mean Household Vehicle Availability ...................................................... 27

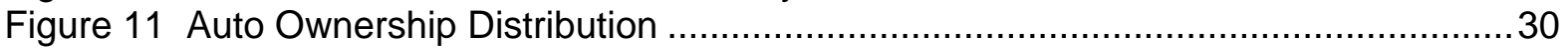

Figure 12 Derived Study Area Base Vehicle Allocation Matrix ...................................... 30

Figure 13 Household Vehicle Ownership Distribution............................................... 31

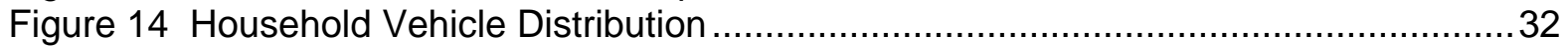

Figure 15 Household Expenditure on Travel by Ownership Vehicle Distribution.................33

Figure 16 Household Savings by Ownership Vehicle Distribution ................................... 34

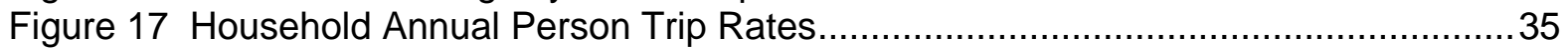

Figure 18 Household Travel Behavior Analysis ..................................................... 36

Figure 19 Transit Trips for Households with Relinquished Vehicle .................................36

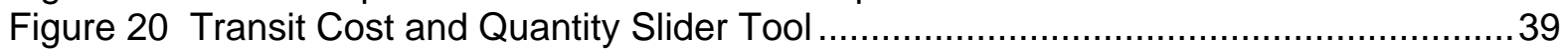

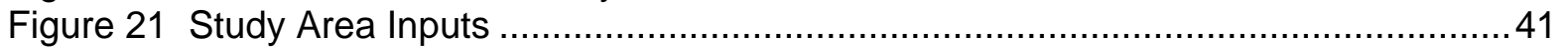

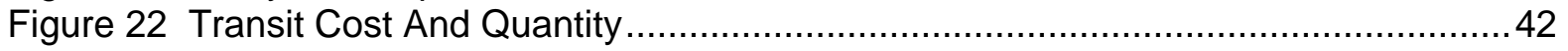

Figure 23 Output Matrix From Transit Tool .............................................................. 43

Figure 24 Changes in Vehicle Ownership Affecting Transit Travel ................................43

Figure 25 Transit Ridership with 2.5 and 7.5 Percent Reduction in Household Vehicles .... 45

Figure 26 Transit Ridership with 2.5 and 7.5 Percent Reduction in Household Vehicles ....46

Figure 27 Household Vehicle Distribution with Reduced Mean Vehicle Ownership ...........47

\section{LIST OF TABLES}

Table 1 Auto Travel Baseline Cost, 2003 (Cents per Mile) ........................................ 7

Table 2 Housing and Transportation Expenditure by Income Class ................................. 8

Table 3 Trends in Personal Travel, National Travel Survey ........................................... 9

Table 4 Household Expenditure by COICOP Category, England ................................. 12

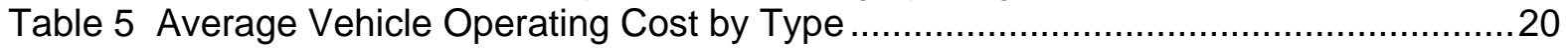

Table 6 Average per Mile Cost of Owning and Operating Private Cars ..............................21

Table 7 US Average Transportation Expenditure Growth over Time ...............................23

Table 8 Comparison of Mode Change versus Auto Availability ....................................48 


\section{INTRODUCTION}

Despite continued and growing public support of public transit over the last several decades, traffic congestion continues to grow worse. Transit ridership and service levels have grown, but not sufficiently to play a more meaningful role in addressing growing travel demands and congestion levels. As a result, interest continues in exploring how significant transit service increases might provide adequate transit capacity and sufficiently attractive service levels to attract more riders to transit and simultaneously offset the need of households for continuing the high current auto ownership levels. Similarly, policy analysts speculate that the resources saved by households with fewer autos may represent a sufficient consumer benefit to justify or offset the higher subsidy costs necessary to provide the enhanced transit services. While speculation on this topic is common among transit planners and advocates, the literature currently offers little insight into this issue.

\subsection{Objectives and Supporting Tasks}

This study explores several data sets to develop an understanding of the economic and travel implications that might arise in households if there were reduced auto ownership in response to better transit service or other policy initiatives targeting reduced auto ownership. Using several data sets including the Bureau of Labor Statistics (BLS) Consumer Expenditure Survey data, the 2001 National Household Travel Survey (NHTS) travel data, the National Transit Database (NTD), and the American Community Survey data on vehicle ownership, this research provides information to support policy discussions regarding the prospect of developing more transit-intensive urban environments in conjunction with lower household vehicle ownership and use costs. The results add a very helpful perspective regarding the potential and economics of programs that propose more transit-friendly and transit-intensive urban environments.

The following are brief summaries of the tasks that comprise this research. The project was carried out by the National Center for Transit Research at the USF Center for Urban Transportation Research and was supported by the Florida Department of Transportation, Office of Public Transportation research work program. 


\section{Task 1: Determine Average Auto Operating Costs}

This task explored household vehicle ownership costs over time and across geographies. The objective was to develop an understanding of vehicle ownership/operating cost characteristics as a function of vehicle availability and household size characteristics.

\section{Task 2: Explore Marginal Vehicle Ownership/Operating Savings and} Travel Behavior Changes Expected from Relinquishing a Vehicle

This task explored marginal vehicle ownership costs for subsequent vehicles in multi-vehicle households. This included understanding the probable change in use and costs of remaining household vehicles and required exploring how travel previously made in a second or subsequent vehicle would be redistributed as vehicle ownership levels were reduced.

\section{Task 3: Scenario Analysis}

This task developed scenarios to test the economic and market acceptance of transit intensive scenarios that include lower household vehicle ownership costs and higher levels of public transportation service. Scenarios were developed to contrast household savings for various lower rates of auto ownership against the public cost for better transit service and the probable diversion of travel demand to public transit. This included reviewing the capacity and service improvements in transit that might be afforded by various levels of shifting or capturing some of the household auto ownership savings to be used for public transportation service investments.

\section{Task 4: Final Report}

This task consisted of compiling the research findings into this final report.

\subsection{Project Logic}

Early in the project, an overall project logic outline was established to guide the activities. Figure 1 outlines the logic flow diagram. This flow diagram broke tasks into components and specified the data requirements. It became clear that the mechanism for implementing the logic of the flow chart would be to build a spreadsheet to use to process the data and capture the interactions. Accordingly, an Excel spreadsheet was developed that was designed to incorporate the data noted in the flow diagram. The remainder of this report 
includes a literature review in Chapter 2, a discussion of vehicle ownership costs in Chapter 3 , a description of the spreadsheet in Chapter 4 and the research scenarios and observations in Chapter 5.

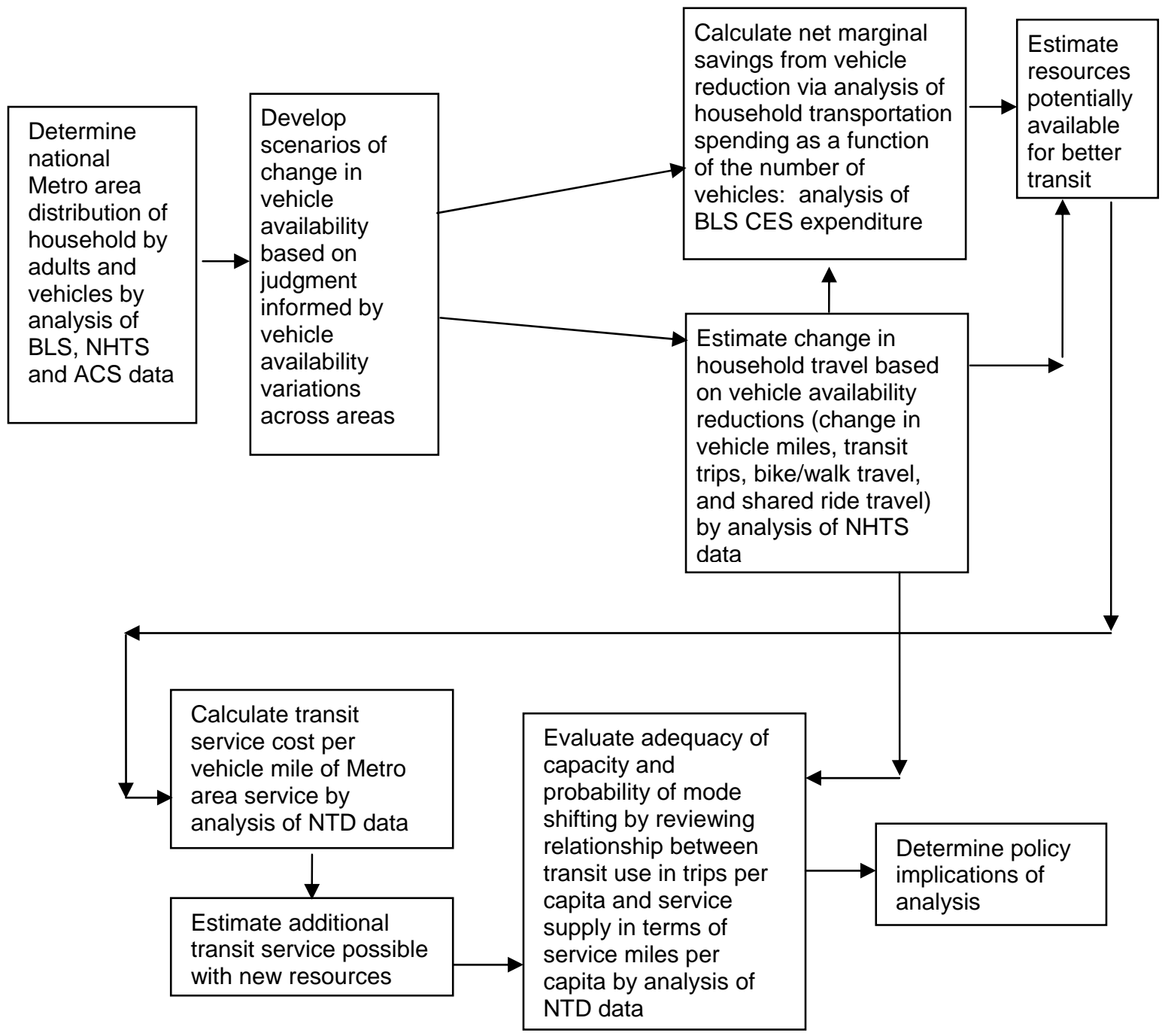

Figure 1 Analysis of the Potential Impacts of Reduced Vehicle Ownership 


\section{LITERATURE REVIEW}

The growth of cities over the decades has occurred concurrent with an increase of automobiles, which brings with it, increased congestion, emissions, and consumption of energy. In addition, growing auto availability and dependency has supported the trend toward urban sprawl, resulting in an automobile-dependent population living in the urban fringe, thus reducing reliance on public transportation despite the measures taken by the government to support public transportation. The trend in auto ownership in the US has shifted to where people no longer think in terms of household vehicle availability but rather think in terms of individual vehicle availability. This trend has compounded the challenge for transit, as it is increasingly difficult to offer sufficiently attractive transit service to be an appealing alternative to drivers who have an auto available.

Transit professionals often refer to a downward spiral of transit service; declines in ridership result in poor productivity, which leads to service cuts and fare hikes which eventually spur a subsequent round of reduced ridership. This cycle continues absent intervention of an outside factor that can stop or reverse the trend. One such outside intervention is policy initiatives to meaningfully enhance transit service such that the quality of service is sufficiently attractive to stop or reverse the trend toward auto reliance. Analysts have postulated several mechanisms for such a trend change, from a meaningful increase in service funding, to urban redesign intended to increase density and provide design characteristics to favor transit use, to policy initiatives to encourage reduced car ownership and subsequently greater transit use. While this research is not designed to explore the feasibility of the various mechanisms or their public acceptability, it is designed to explore the financial and travel behavior implications of changes in auto availability and transit service supply.

The American Public Transportation Association (APTA) announced an increase of 50 million trips by public transportation in the last quarter of 2007, a 2 percent increase over the previous year. This growth in public transportation ridership is attributed to the strong economy, federal, state and local investments in enhanced service, higher gas prices, and population growth. According to APTA, ${ }^{1}$ Americans in public- transportation-intensive areas save about $\$ 22$ billion each year in their annual transportation costs. 


\subsection{Problem Statement}

With the ever-increasing dependence on private transportation and higher vehicle miles of travel, there is an interest in exploring the prospect of complementary initiatives that would encourage reduced auto ownership which could produce cost savings for participating households and then attempt to capture some of that savings such that additional resources could be invested in public transportation. The interest in these types of initiatives is enhanced by growing concerns about housing affordability, financial pressures associated with very high cost gasoline, and ongoing concerns about emissions and the suspected link to climate change. The goal of reduced auto use has been recognized in federal legislation such as the Clean Air Act and the Intermodal Surface Transportation Efficiency Act, and their subsequent amendments and reauthorizations. ${ }^{2}$

\subsection{Background}

The Bureau of Labor Statistics (BLS) reported the combined costs of housing and transportation to be 51.8 percent in 2003 , which is relatively high compared to the previous years and affirms the growing public interest in this issue. In recent years, the Surface Transportation Policy Project (STPP) and the Center for Neighborhood Technology (CNT) have been studying the rising cost of transportation and its effects on US households as part of their efforts to promote livable communities and support urban revitalization. ${ }^{3}$

Various bodies of literature have explored elements of auto ownership and transit use that shed light on the issues key to this research. One of the concepts that embraces this linkage is Location Efficient Mortgages (LEM). ${ }^{4}$ This allows the public to purchase a home in a transit-oriented location by allowing higher mortgage debt levels based on the presumption that higher household expenditures for housing will be possible because households can reduce their household auto ownership costs as a result of living in proximity to transit. In simple terms, it redeploys the amount in dollars saved on transportation by living in communities that have a well-connected public transit system to allocate additional resources to support home ownership. A location efficient mortgage increases the housing buying power of the public, thus creating an incentive for residential location in proximity to transit. Currently, LEM communities are available in four cities: San Francisco, Los Angeles, Seattle, and Chicago. LEM is a unique strategy for mitigating auto dependency while supporting transit-friendly development patterns. 
The growth of cities from urban to suburban areas has influenced car ownership trends over the years. Matt and Timmermans, ${ }^{5}$ who studied the nature of car ownership in relation to residential and work location, showed that people in lower density rural and suburban areas with greater distance to amenities and less public transportation found it necessary to own more private cars as compared to people in urban areas. The higher cost of parking, limited space, congestion, and higher insurance premiums in the urban areas were added reasons for urban residents to reduce car ownership. Memmott ${ }^{6}$ studied the factors contributing to the rapid rise in passenger car travel and concluded that the increase in income was a principal factor that contributed to households acquiring more personal vehicles and families shifting to suburban housing with longer commute trip distance as well as more discretionary trips.

The STPP report Driven to Spend compared the expenditure on gasoline by low and high income households and found an uneven impact on the low income households with respect to the expenditure on transportation, particularly when gasoline prices are high. Thus, a household with average household income less than $\$ 50,000$ would spend around 4 percent of their income on transportation fuel (approx \$2,000), compared to a household with twice the annual income spends only about 2.3 percent on transportation fuel. ${ }^{3}$

Past studies conducted on the effect of household income on transportation expenditure throws light onto various factors that affect the nature of car ownership by households. The study conducted by Ramjerdi, Rand, and Saterm ${ }^{7}$ on household car ownership modeling indicated that higher income households lead to shorter duration of vehicle ownership, which is due to the fact that those households can easily replace older cars. The report also studied the average age of car ownership and indicated that the newer car is retained longer for households with more than one car. Other factors influencing the nature of car ownership and auto dependency are land use and tax policy.

Researchers have thrown light on the policy implications affecting the nature of automobile use in the country. Pucher ${ }^{8}$ compared the differences in transport policies, which showed that the transit use per capita in Western Europe and Canada to be as much as four times that in the United States (77 to 114 trips in Europe vs. 28 in United States), which is mainly due to the low population density in the United States. Pucher points out that the low gasoline taxes in the United States, the lower parking rates, and the ease in obtaining 
driver's licenses, federal government mortgage guarantees, and tax deductions that encourage subsidies to home ownership and suburbanization, and the American policies that do not require the auto users to bear the full social and environmental costs all have supported auto ownership in United States cities. The compactness of land use in many European, Canadian, and Australian cities also encourages greater use of transit; yet some American cities such as Detroit and Los Angeles that have inner area population density comparable to that of Toronto provide only one-fifth the transit service per person. Newman and Kenworthy ${ }^{9}$ suggested reorientation of some transportation policies in the United States such as upgrading and extending transit by favoring transit-oriented development that provides easy access to transit, and planned or tolerated congestion, which ultimately may discourage the use of private automobiles thus giving priority to public transportation modes.

An analysis of the 1990 National Personal Travel Survey about the travel trends and behavior in the United States showed that there has been a significant decrease in vehicle occupancy for work-related trips and a higher number for long distance trips. ${ }^{10}$ This study also looked at the significant increase in average distance traveled, which could be due to the increase in auto ownership, higher incomes, more licensed owners per household, and the overall size of metropolitan areas. Barnes and Langworthy studied the cost of owning and operating personal vehicles by dividing the cost into five major components: fuel, maintenance (excluding tires), tires, unscheduled repairs, and depreciation. ${ }^{11}$ From the study it can be seen that the cost of fuel (32.7\%) and depreciation (40.5\%) contribute significantly to the cost of owning and operating private cars. Table 1 shows the cost for automobiles, pickups/vans/SUVs, and trucks. This study excludes insurance and financing costs and shows noticeably lower total costs than other studies but serves to provide data on the differences across vehicle types and component shares.

Table 1 Auto Travel Baseline Cost, 2003 (Cents per Mile)

\begin{tabular}{|c|c|c|c|}
\hline Cost Category & Automobile & $\begin{array}{c}\text { Pickup/ Van/ } \\
\text { SUV }\end{array}$ & $\begin{array}{c}\text { Commercial } \\
\text { Truck }\end{array}$ \\
\hline Total & 15.3 & 19.5 & 43.4 \\
\hline Fuel & 5.0 & 7.8 & 21.4 \\
\hline Maintenance/Repair & 3.2 & 3.7 & 10.5 \\
\hline Tires & 0.9 & 1.0 & 3.5 \\
\hline Depreciation & 6.2 & 7.0 & 8.0 \\
\hline
\end{tabular}

Source: Per Mile Cost of Operating Automobiles and Trucks; Barnes G. and Langworthy P.; Submitted to the Humphrey Institute of Public Affairs, University of Minnesota, July 2003. 
A primary aim of Transit Oriented Development (TOD) is to provide better housing affordability near quality transit service. TOD research has shown that transportation costs create a major burden on working families; especially for those who earn $\$ 50,000$ or less a year, with the expenditure on transportation equaling or exceeding the expenditure on housing. It could also be seen that these costs depend on the location of housing and the workplace. Hence, policy reforms should be targeted to reduce the combined costs of transportation and housing, such as improving public transportation to serve moderateincome working families to their common work destinations, providing connections between densely populated suburbs, and the redevelopment of inner cities and suburbs near job locations, which can increase density as well as improve transportation ridership. ${ }^{12}$ The Center for Housing Policy recommends that, by targeting job opportunities in inner ring suburbs and also building affordable housing near planned and existing transportation hubs, household spending on transportation can be reduced.

Table 2 Housing and Transportation Expenditure by Income Class

\begin{tabular}{|l|c|c|c|c|c|c|}
\hline $\begin{array}{c}\text { Annual } \\
\text { Household } \\
\text { Income }\end{array}$ & $\mathbf{\$ 2 0 , 0 0 0}$ & $\begin{array}{c}\mathbf{\$ 2 0 , 0 0 0} \\
\mathbf{t o} \\
\mathbf{\$ 3 4 , 9 9 9}\end{array}$ & $\begin{array}{c}\mathbf{\$ 3 5 , 0 0 0} \\
\mathbf{t o} \\
\mathbf{\$ 4 9 , 9 9 9}\end{array}$ & $\begin{array}{c}\mathbf{\$ 5 0 , 0 0 0} \\
\mathbf{t o} \\
\mathbf{\$ 7 4 , 9 9 9}\end{array}$ & $\begin{array}{c}\mathbf{\$ 7 5 , 0 0 0} \\
\mathbf{t o} \\
\mathbf{\$ 9 9 , 9 9 9}\end{array}$ & $\begin{array}{c}\mathbf{\$ 1 0 0 , 0 0 0} \\
\mathbf{t o} \\
\mathbf{\$ 2 5 0 , 0 0 0}\end{array}$ \\
\hline Housing & $58 \%$ & $31 \%$ & $24 \%$ & $20 \%$ & $17 \%$ & $14 \%$ \\
\hline Transportation & $56 \%$ & $34 \%$ & $24 \%$ & $18 \%$ & $13 \%$ & $8 \%$ \\
\hline $\begin{array}{l}\text { Combined } \\
\text { Expenditure }\end{array}$ & $114 \%$ & $65 \%$ & $48 \%$ & $38 \%$ & $30 \%$ & $22 \%$ \\
\hline
\end{tabular}

\subsection{European Experiences}

The National Travel Survey (NTS) provides data on personal travel information in Great Britain, limited to England, Wales, and Scotland. It has been conducted as a continuous survey since 1988 to identify the long-term trends in personal travel. The survey, based on the random sampling method, had approximately 8,400 respondent households for the interview who completed trip diaries, which have been weighted to give an estimate of the average travel trends in the country. Some of the basic characteristics of the sample are given in Table 3. 
Table 3 Trends in Personal Travel, National Travel Survey

\begin{tabular}{|c|c|c|c|c|}
\hline Year & $\begin{array}{l}\text { Trip Distance } \\
\text { (miles) }\end{array}$ & Total Trips & $\begin{array}{c}\text { Average Time } \\
\text { (minutes) }\end{array}$ & $\begin{array}{c}\text { Average } \\
\text { Distance (miles) }\end{array}$ \\
\hline 1995 & 6981 & 1086 & 20.4 & 6.4 \\
\hline 2000 & 7164 & 1071 & 21.1 & 6.7 \\
\hline 2002 & 7135 & 1047 & 21.8 & 6.8 \\
\hline 2004 & 7103 & 1026 & 22.3 & 6.9 \\
\hline 2005 & 7208 & 1044 & 22.1 & 6.9 \\
\hline
\end{tabular}

NTS reported that car availability rose from 77 percent in 1995/97 to about 81 percent in 2005. Figure 2 shows auto availability as a function of urban development type. Similarly, personal travel by car/van increased by about 2 percent, while travel by other modes such as light rail, surface rail, and taxi rose up by 13,44 , and 30 percent, respectively. The average travel distance for person-travel increased by about 30 percent in the last 30 years, which is a combined result of the average trip lengths and the number of person trips made each year. ${ }^{13}$ Time spent in travel in 2005 is about 385 hours, which is about 4 percent more than in 1995/97. In 2005, four out of every five trips were made by car. Comparing the trends in car ownership over the years, it can be seen that the number of households without any car fell by nearly 20 percent from 1985/87 to 2005, with only about 25 percent of households without any car. Figure 3 shows the difference in car availability based on the area of residence, which shows that people living in large urban and metro areas more commonly manage without a car compared to people in rural areas. 


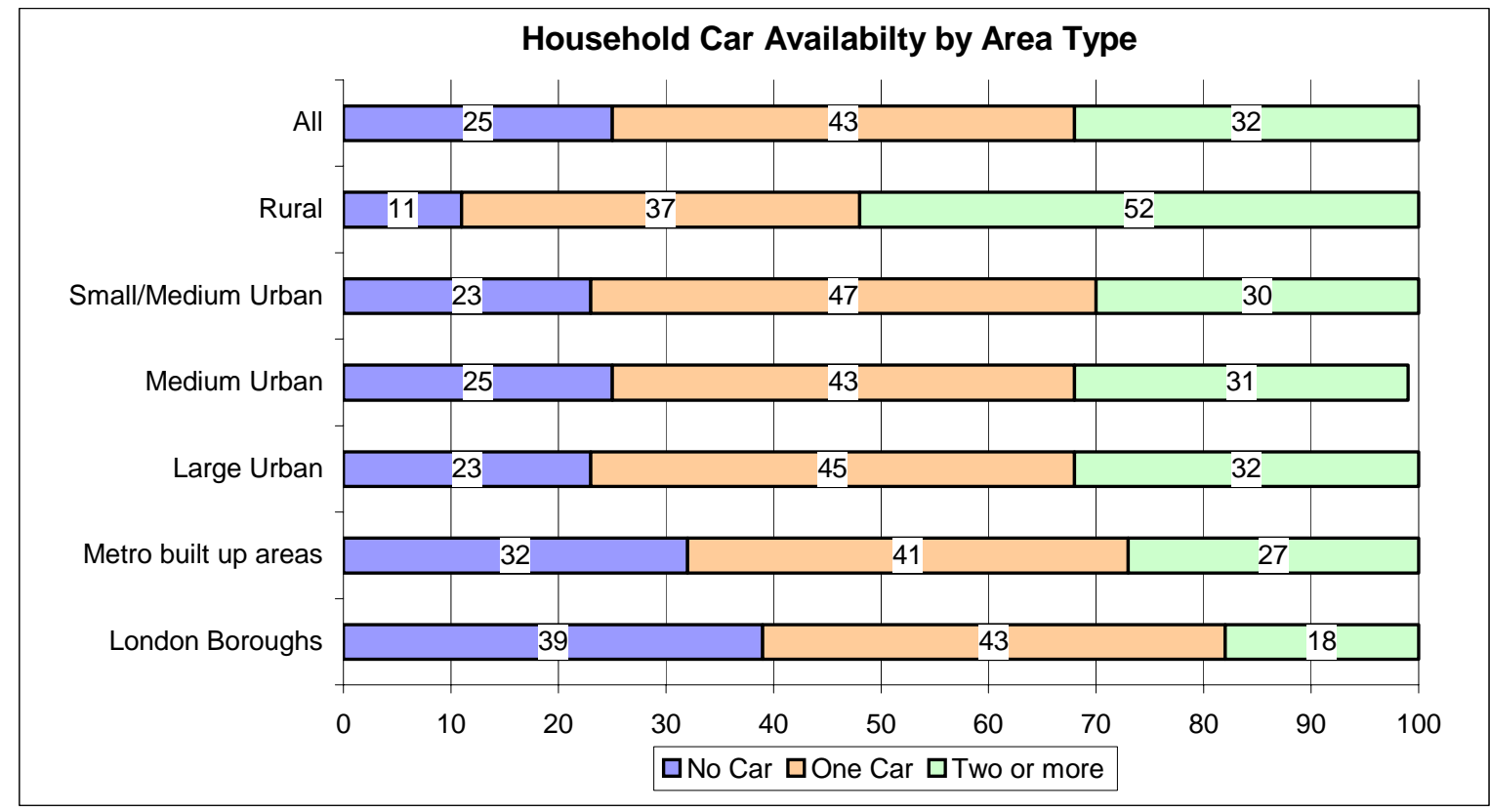

Figure 2 NTS Household Car Availability by Area

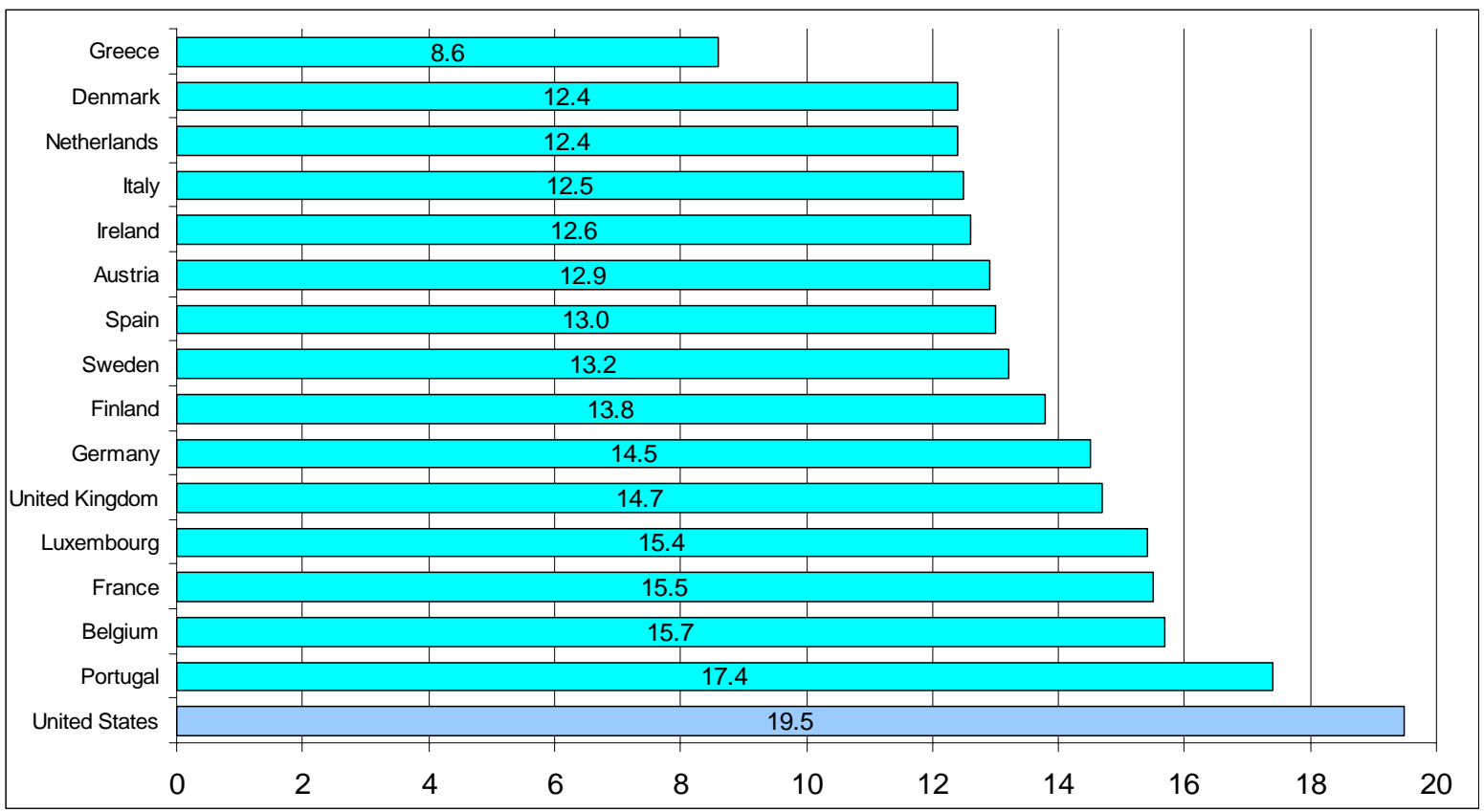

Figure 3 Transportation as a Percent of Household Expenditures in Europe

Source: Eurostat, National Statistical Offices

Website: http://www.statistics.gov.uk/STATBASE/Expodata/Spreadsheets/D7236.xls

and Transportation Statistics Annual Report, 2001,

Website:http://www.bts.gov/publications/transportation statistics annual report/2001/excel/chapter 07 table 01 200.xls

The Family Spending: 2006 edition gives an overview of consumer spending in 2005. 
Figure 4 compares the average transportation expenditure for the European countries represented as a percentage of total household income.

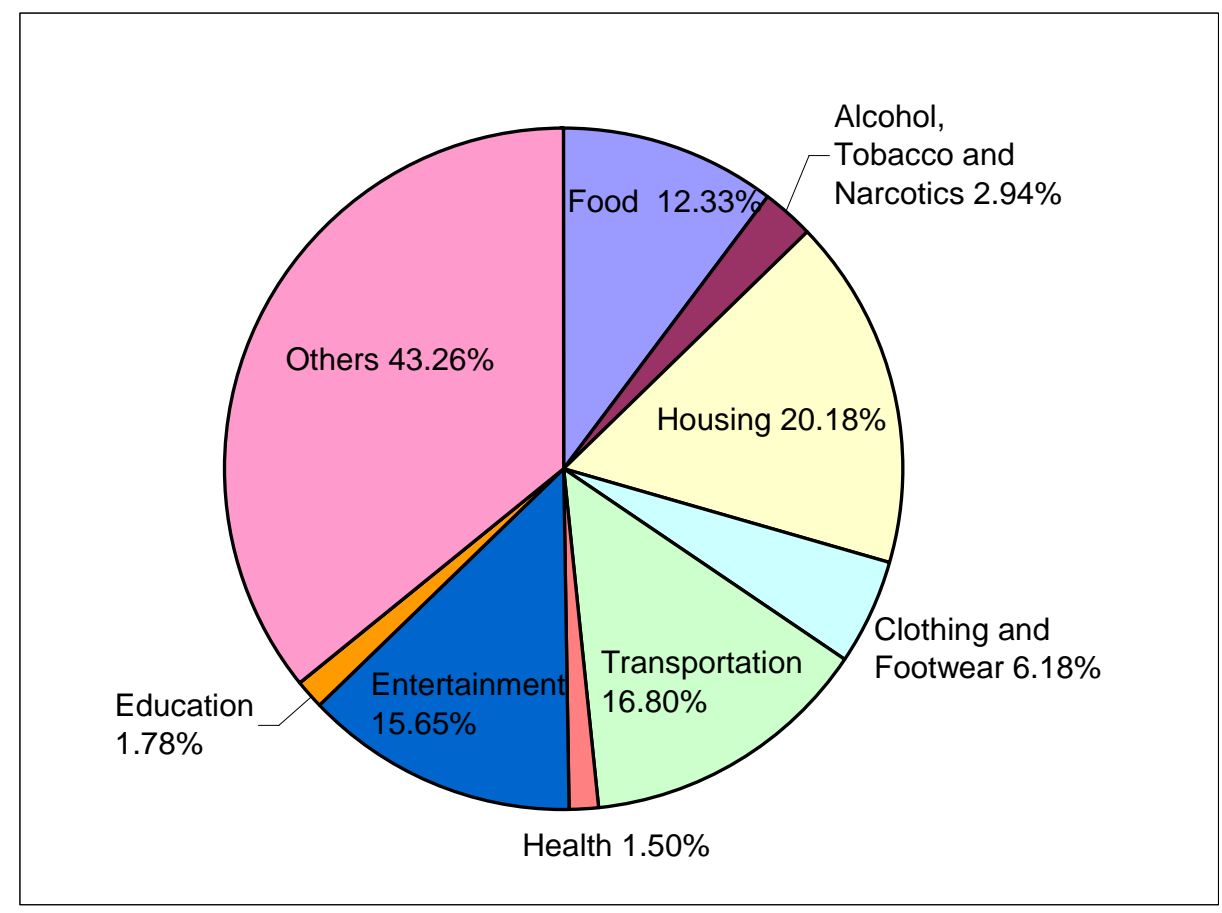

Figure 4 Average Household Expenditures, England, 2005

The nature of spending by the households in the UK can be very closely compared to consumer expenditures in the US for the year 2005. Figures 5 and 6 compare US and UK households' average household transportation expenditures as a percent of total expenditures to give a better idea of the consumer spending in both countries for various categories. The charts attempt to closely capture similar elements of the spending categories for the year 2005 based on the NTS and the BLS survey information for the United Kingdom and the United States, respectively. 
Table 4 Household Expenditure by COICOP Category, England

\begin{tabular}{|l|c|c|}
\hline Household Expenditure Category & £ per Week & Percent \\
\hline Transport & 61.75 & 16.8 \\
\hline Recreation and culture & 57.53 & 15.7 \\
\hline Food and non-alcoholic drinks & 45.31 & 12.3 \\
\hline Housing, fuel, and power & 44.17 & 12.0 \\
\hline Restaurants and hotels & 36.70 & 10.0 \\
\hline Miscellaneous goods and services & 34.63 & 9.4 \\
\hline Household goods and services & 30.01 & 8.2 \\
\hline Clothing and footwear & 22.73 & 6.2 \\
\hline Communication & 11.90 & 3.2 \\
\hline Alcoholic drinks, tobacco, and narcotics & 10.80 & 2.9 \\
\hline Education & 6.56 & 1.8 \\
\hline Health & 5.50 & 1.5 \\
\hline Total Expenditure based on COICOP & 367.58 & \\
\hline Source: Office of National Statistics Household Expenditure: Summary by COICOP Group; Aug 2006. \\
\hline
\end{tabular}

\footnotetext{
${ }^{1}$ From 2001-02, the Classification of Individual consumption by Purpose (COICOP) was introduced as a new coding frame for expenditure items. COICOP is the internationally agreed classification system for reporting household consumption expenditure.
} 


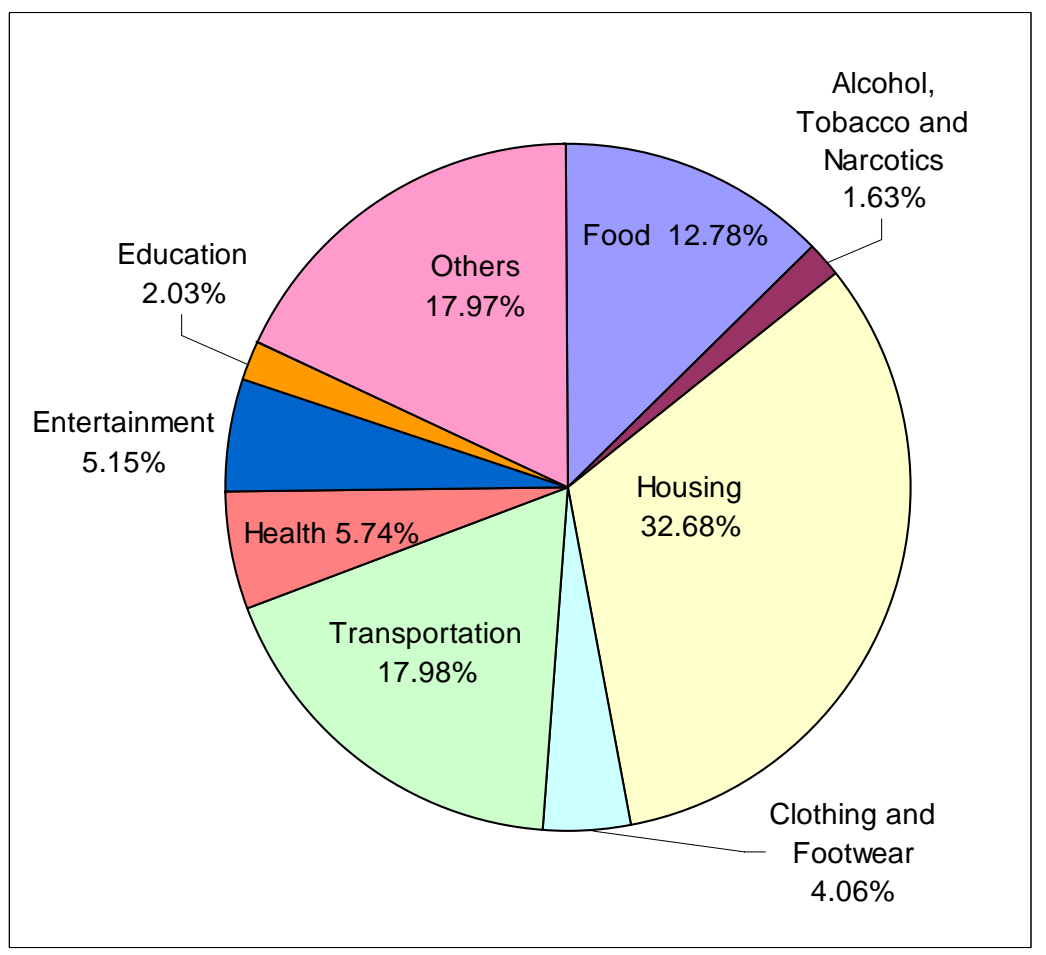

Figure 5 Average Household Expenditure for US, 2005

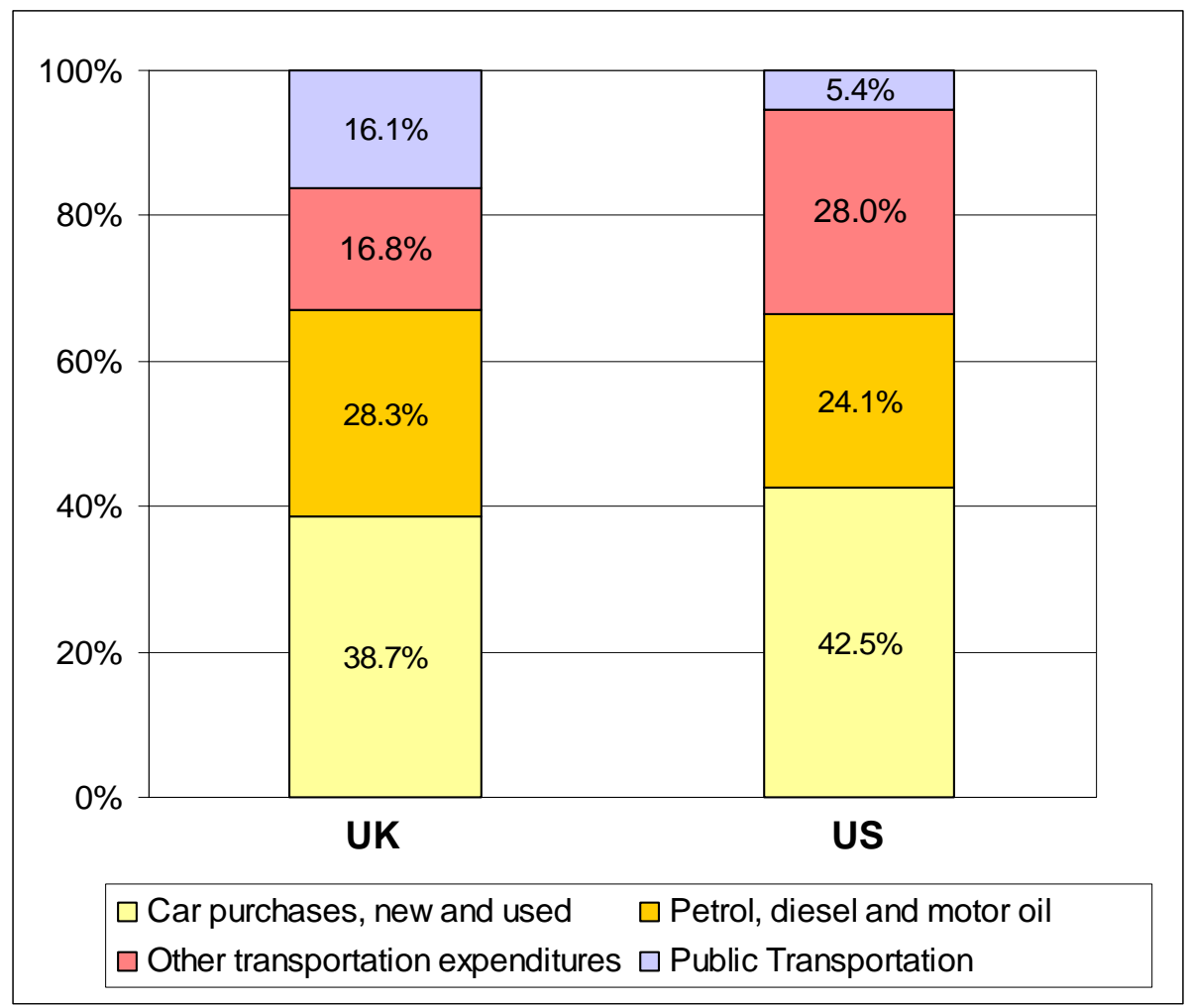

Figure 6 Household Transportation Spending by Category for US and UK 
It can be seen from charts 4 and 5 that transportation expenditures are comparable for both the UK and US, while the expenditure on housing accounted for nearly 32 percent in the United States compared to about 20 percent in the United Kingdom. Of the average expenditure spent on transportation in UK, £61.70 a week, about 45 percent was spent on personal transportation and operation ( $£ 27.90)$, approximately 28 percent ( $£ 17.50)$ was spent on motor fuels and oil, and around 16 percent (£9.90) was spent on public transportation services like rail, bus, etc. It should also be noted that households with high incomes spent about 16 percent on transportation while the low income households spent only about 9 percent on transportation.

Figure 6 compares the nature of transportation spending in households based on the NTS and the BLS survey information for 2005 for United Kingdom and United States, respectively. It can be seen that people in the United Kingdom use more public transportation as compared to the United States, which shows a significant difference in the transportation expenditure. Note that in both countries individuals travel spending changes as a function of income with the share of transportation spending less sensitive to income in the US than in England.

Figure 7 compares housing and transportation expenditures for the US and UK based on income percentile for the year 2006. It is evident from the graph that, on average, US households spend almost double their annual income on housing and transportation expenditures compared to the UK households. 


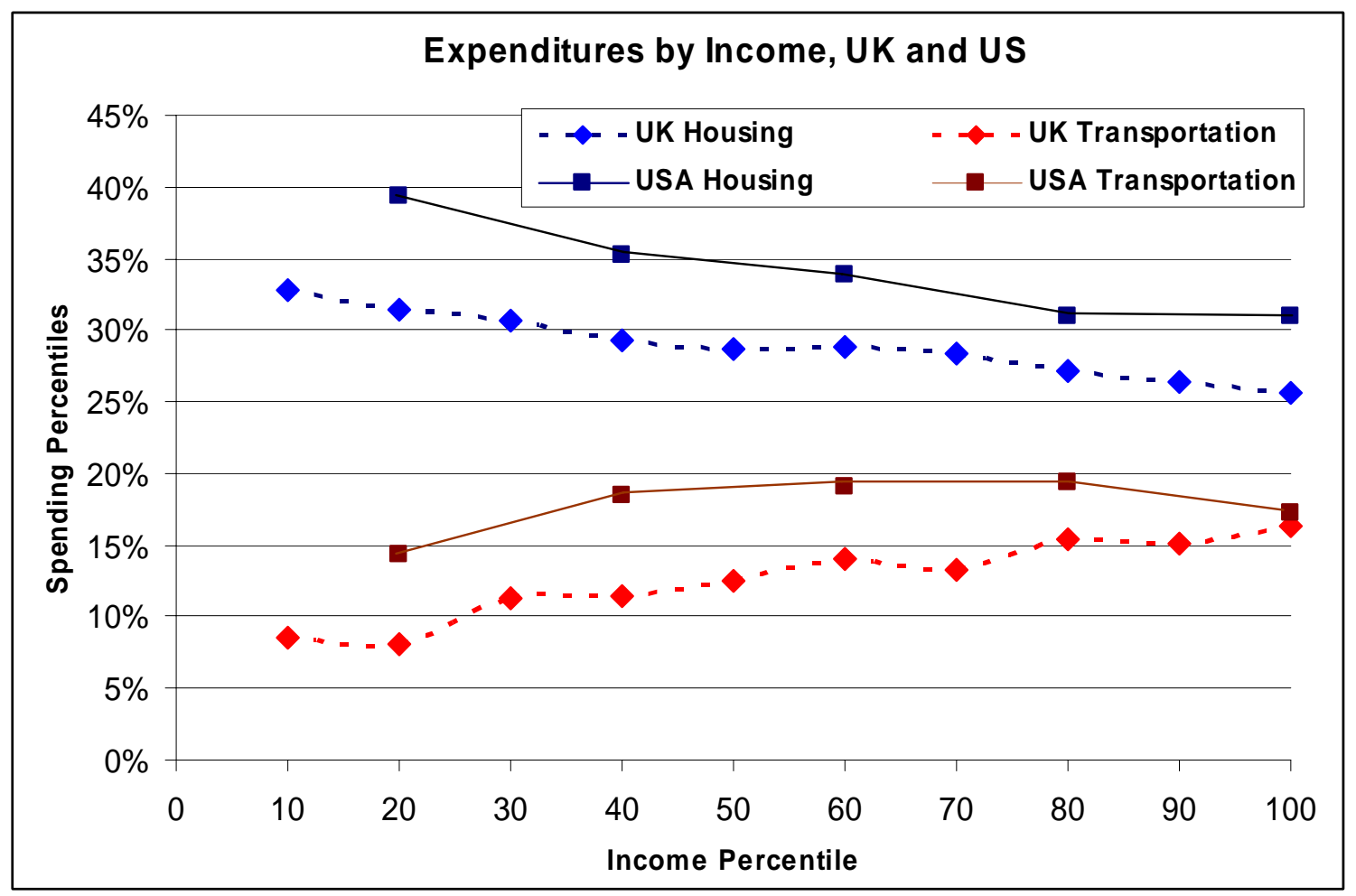

Figure 7 Comparison of Housing and Transportation Expenditure for UK and US

In the UK, housing expenditure includes housing net expenses. These include the actual rental expenses, maintenance and repair of dwelling, water supplies and miscellaneous supplies related to dwelling, electricity, gas and fuels, housing goods and services;(the furniture and furnishings, carpets, and goods and service for routine maintenance), and the housing mortgage, interest payment, taxes, etc. Transportation expenses include purchase of new and used vehicles, maintenance, repairs, oil, fuel expenses and public transportation expenses including subway, rail, bus, and coach fares.

US housing expenditures include the costs of shelter such as ownership, mortgage, property taxes, maintenance and repair charges, utilities, fuels and public services, household operations and associated expenses, housing supplies, furniture, furnishings, and equipment. Transportation costs include the cost of new and used vehicles, maintenance, repairs and cost for gasoline and motor oil, other expenses such as insurance, rental, lease, finance charges, and spending on public transportation.

\subsection{Data Sources for Analysis}


Basic data to support this research come from four different sources: the 2001 National Household Travel Survey, the BLS Consumer Expenditure Survey, the National Transit Database, and the American Community Survey. Each of these sources is briefly described below, and descriptive data are provided.

Various datasets have been used in the analysis of household expenditure, especially for spending on transportation. The Consumer Expenditure Survey, Bureau of Labor Statistics, and the Bureau of Transportation Statistics provide information on the nature of consumer spending in the United States.

\subsection{Consumer Expenditure Survey}

The Bureau of Labor Statistics (BLS) conducts different surveys based on employment characteristics, living and working conditions, productivity, and technology. The Consumer Expenditure Survey (CES) is collected for the Bureau of Labor Statistics by the Census Bureau. It provides data on the expenditure, income, and consumer unit characteristics of households. The survey is conducted in two parts, a Quarterly Interview Survey and a Weekly Diary Survey, each with its own questionnaire. The annual report, published at the end of the year following the survey, consists of integrated results from the survey and provides essential information on the nature of consumer spending, the historical expenditure trends in US, and spending by different households in relation to their income and other socioeconomic characteristics.

\subsubsection{Diary Survey}

Also called the recordkeeping survey, the Diary Survey collects data from the consumer units (CU) for 2 consecutive weeks during the 12-month period. It contains expenditure records for small, frequently-purchased items in the household where the CU can keep a record of it for a one-week period. The Diary Survey includes weekly expenditures of frequently purchased items such as food and beverages, tobacco, personal care products, and nonprescription drugs and supplies. 


\subsubsection{Interview Survey}

New groups of respondents are initiated every three months (Panels A, B, and C), and each $\mathrm{CU}$ is interviewed once in three months. The CUs are subjected to five interview sets after which the panel is dropped. The Diary Survey collects data on major expenditure categories, covering almost 60 to 70 percent of household expenditures. The interview survey covers out-of-pocket expenditures on housing, transportation, healthcare, insurance and entertainment. The first interview covers demographics and family characteristics data which include age, sex, race, marital status, education, CU interrelationship, etc. The information is updated for every subsequent interview, which include the expenditures for the month prior to the interview. The second interview uses a uniform questionnaire to collect expenditure information from the $\mathrm{CU}$ from the past three months. Income information, such as wage, salary, unemployment compensation, child support, and alimony, as well as information on the employment of each CU member age 14 and over, are collected in the second and fifth interviews only. The third and fourth interviews collect income and expenditure information carried over from the second interview. Additional data in the third and fourth interviews are only from new CUs who have started new since the previous interview. The fifth interview uses a supplement to collect information on asset values and changes in balances of assets and liabilities. These data, along with other household characteristics information, permit users to classify sample units for research purposes and allow BLS to adjust population weights for CUs who do not cooperate in the survey.

The CUs are rotated after every fifth interview primarily to improve the quality of the data; thus 20 percent of the sample is changed every year. The unit of analysis for the Consumer Expenditure Surveys is the consumer unit, which consists of either (i) all members of a particular housing unit who are related by blood, marriage, or adoption, (ii) people living and sharing a household with others, but who are financially independent, or (iii) two or more living together and sharing their income to make joint expenditures.

\subsubsection{Cooperation Levels/Sample Numbers}

Out of the 49,242 CUs designated for the survey, 18.8 percent were ineligible cases, which were either vacant, nonexistent houses, or ineligible CUs for the survey. From the 
remaining interviewers, 25.5 percent were non-responsive candidates, which resulted in 29,804 responsive interviews.

\subsection{Weighting}

Each CU in the interview represents a particular number of CUs in the US population, which is considered as the universe. Conversion of the sample families into the universe families is called "weighting." The weight given to a CU can be different in different quarters in which the CU participates, as it would represent different number of households with similar characteristics.

\subsection{Data Interpretation}

The spending characteristics of a CU may be different due to income, age, geographic location, and personal preferences. It could also be more or less than the average based on the $\mathrm{CU}$ characteristics. Expenditures data reflect direct out-of-pocket expenditures, while the indirect expenditures may be reflected in some other data values.

It is to be noted that BLS uses the term "consumer unit" rather than household. BLS defines a consumer unit as 1) members of a household related by blood, marriage, adoption, or other legal arrangement; 2) a person living alone, sharing a household with others, or rooming in a private home, lodging, or in permanent living quarters in a hotel or motel but who is financially independent; or 3) two or more persons living together and making joint expenditure decisions. Students living in university-sponsored housing are also included in the sample as separate consumer units. ${ }^{14}$ 


\section{AVERAGE AND MARGINAL COSTS OF AUTO OWNERSHIP}

This chapter examines the average costs of automobile ownership in the country over the years, based on the results of the NHTS 2001 survey and the BLS Consumer Expenditure Survey to develop a better understanding of the transportation costs as a function of household characteristics and vehicle availability and also as a percent of household income. It also focuses on estimating the marginal costs, which helps in the future sections of the report for calculating the redistributed trips and the savings incurred by reducing the number of vehicles in the household.

\subsection{Average Costs}

Vehicle costs can be divided into fixed cost and variable cost. The fixed costs, also called ownership costs, generally remain the same. The variable cost, also called operating or marginal cost, increase according to the use of vehicle (vehicle mileage). Fixed costs include vehicle purchase or lease, insurance, registration and vehicle taxes. Variable costs include maintenance and vehicle repair, gas and motor oil, and parking costs and tolls. ${ }^{15}$ Of these costs, only the variable costs are reduced when the total number of vehicle miles is reduced as it accounts for reduction in oil, gas and other motor costs. There is no difference in ownership and insurance costs. Data indicate a saving of only $10 \$$ per reduced mile on vehicles averaging 15,000 miles per year.

However, the real costs of driving a car are not just fuel and oil costs, they include the external costs or the environmental and social costs incurred. Transportation costs are categorized as follows: ${ }^{15}$

- Internal and external impact costs that are costs directly and indirectly affecting the customers, respectively. Internal costs would include vehicle ownership and operating costs, travel time costs, etc. while external costs would include transportation services, cost of providing parking, accidents, etc.

- Market costs include land, fuel and vehicles, which are the costs of goods traded in a market, and non-market costs, which are the costs of goods not regularly traded in 
the market but impact transportation costs like air pollution, land use impacts, noise, congestion, etc.

- Perceived costs are immediate costs like travel time, fuel, parking, etc., while actual costs include insurance, maintenance, and depreciation which often tend to be underestimated.

The Bureau of Economic Analysis (BEA) reports the transportation expenditure to be $\$ 1.09$ Trillion; almost one eighth of the total personal consumption expenditures and very close to the housing expenditure of $\$ 1.38$ trillion. ${ }^{16}$ The average vehicle operating cost per mile as given by the American Automobile Association calculates the operating miles (based on vehicle mileage) and other ownership costs including depreciation costs, to calculate the total cost of owning and operating private cars. ${ }^{17}$

Table 5 Average Vehicle Operating Cost by Type

\begin{tabular}{|c|c|c|c|c|c|}
\hline Type of Automobile and Cost & $\begin{array}{l}\text { Small } \\
\text { Sedan }\end{array}$ & $\begin{array}{l}\text { Medium } \\
\text { Sedan }\end{array}$ & $\begin{array}{l}\text { Large } \\
\text { Sedan }\end{array}$ & SUV & Minivan \\
\hline Gas \& oil & 7.4 & 9.4 & 10 & 12.6 & 10.6 \\
\hline Maintenance & 4.5 & 4.7 & 5.5 & 5.5 & 5.1 \\
\hline Tires & 0.5 & 0.8 & 0.7 & 0.9 & 0.7 \\
\hline Operating costs/mile & $12.4 \Phi$ & $14.9 \phi$ & $16.2 \Phi$ & $14.5 \Phi$ & 16.44 \\
\hline Insurance & $\$ 968$ & $\$ 955$ & $\$ 1,032$ & $\$ 950$ & $\$ 886$ \\
\hline License \& registration & $\$ 401$ & $\$ 544$ & $\$ 668$ & $\$ 695$ & $\$ 587$ \\
\hline Depreciation & $\$ 2,461$ & $\$ 3,394$ & $\$ 4,321$ & $\$ 4,531$ & $\$ 3,899$ \\
\hline Financing & $\$ 527$ & $\$ 743$ & $\$ 743$ & $\$ 971$ & $\$ 807$ \\
\hline Ownership costs/year & $\$ 4,357$ & $\$ 5,636$ & $\$ 6,950$ & $\$ 7,147$ & $\$ 6,179$ \\
\hline Total for 15,000 annual miles & $\$ 6,217$ & $\$ 7,871$ & $\$ 9,380$ & $\$ 9,997$ & $\$ 8,639$ \\
\hline Average cost/mile & $41.4 \phi$ & 52.54 & $62.5 \phi$ & 66.64 & 57.64 \\
\hline
\end{tabular}

It should be noted that fuel costs were based on late 2006 US prices from the AAA Fuel Gauge Report, and the fuel mileage is based on the figures given by the Environmental Protection Agency. Maintenance costs include all the normal, routine maintenance specified by the vehicle manufacturer, while the tires include the costs for replacing the tires with similar quality ones. Of the ownership costs, the insurance is calculated based upon a full- 
coverage policy which includes $\$ 100,000 / \$ 300,000$ coverage with a $\$ 500$ deductible for collision and a $\$ 100$ deductible for comprehensive coverage. Depreciation costs are calculated based on the difference between new-vehicle purchase and the estimated tradein value at the end of five years.

Table 6 gives the average cost of owning and operating automobiles as calculated from the Bureau of Labor Statistics.

Table 6 Average per Mile Cost of Owning and Operating Private Cars

\begin{tabular}{|l|c|c|c|c|c|c|c|c|c|c|c|}
\hline $\begin{array}{l}\text { Cents (in chained } \\
\text { 2000 dollars) }\end{array}$ & $\mathbf{1 9 9 4}$ & $\mathbf{1 9 9 5}$ & $\mathbf{1 9 9 6}$ & $\mathbf{1 9 9 7}$ & $\mathbf{1 9 9 8}$ & $\mathbf{1 9 9 9}$ & $\mathbf{2 0 0 0}$ & $\mathbf{2 0 0 1}$ & $\mathbf{2 0 0 2}$ & $\mathbf{2 0 0 3}$ & $\mathbf{2 0 0 4}$ \\
\hline Variable Costs & 9 & 10 & 10 & 11 & 11 & 11 & 12 & 14 & 12 & 13 & 13 \\
\hline Fixed Costs & 30 & 32 & 33 & 34 & 35 & 36 & 37 & 37 & 38 & 39 & 44 \\
\hline Total Costs & 39 & 42 & 43 & 45 & 46 & 47 & 49 & 51 & 50 & 52 & 57 \\
\hline
\end{tabular}

Source: Bureau of Transportation Statistics, BTS; National Transportation Statistics 2005.

From Table 6, it can be seen that the average variable cost of operating a private car increased by about 4 cents (45\%) in 2004, compared to that of 1994, which is also the same as that of the increase in fixed costs over the years (47\%). ${ }^{18}$ The fixed costs that include purchase, license, registration, and insurance account for over 77 percent of the total costs on the vehicle while the rest only accounts for the cost of gas, oil, and other maintenance expenditures.

Figure 8 gives the average cost of owning and operating private automobiles (fixed and variable costs) as reported by the Bureau of Transportation Statistics. ${ }^{19}$ The figures are based on the average cost of operating a vehicle 15,000 miles per year in stop and go conditions. 


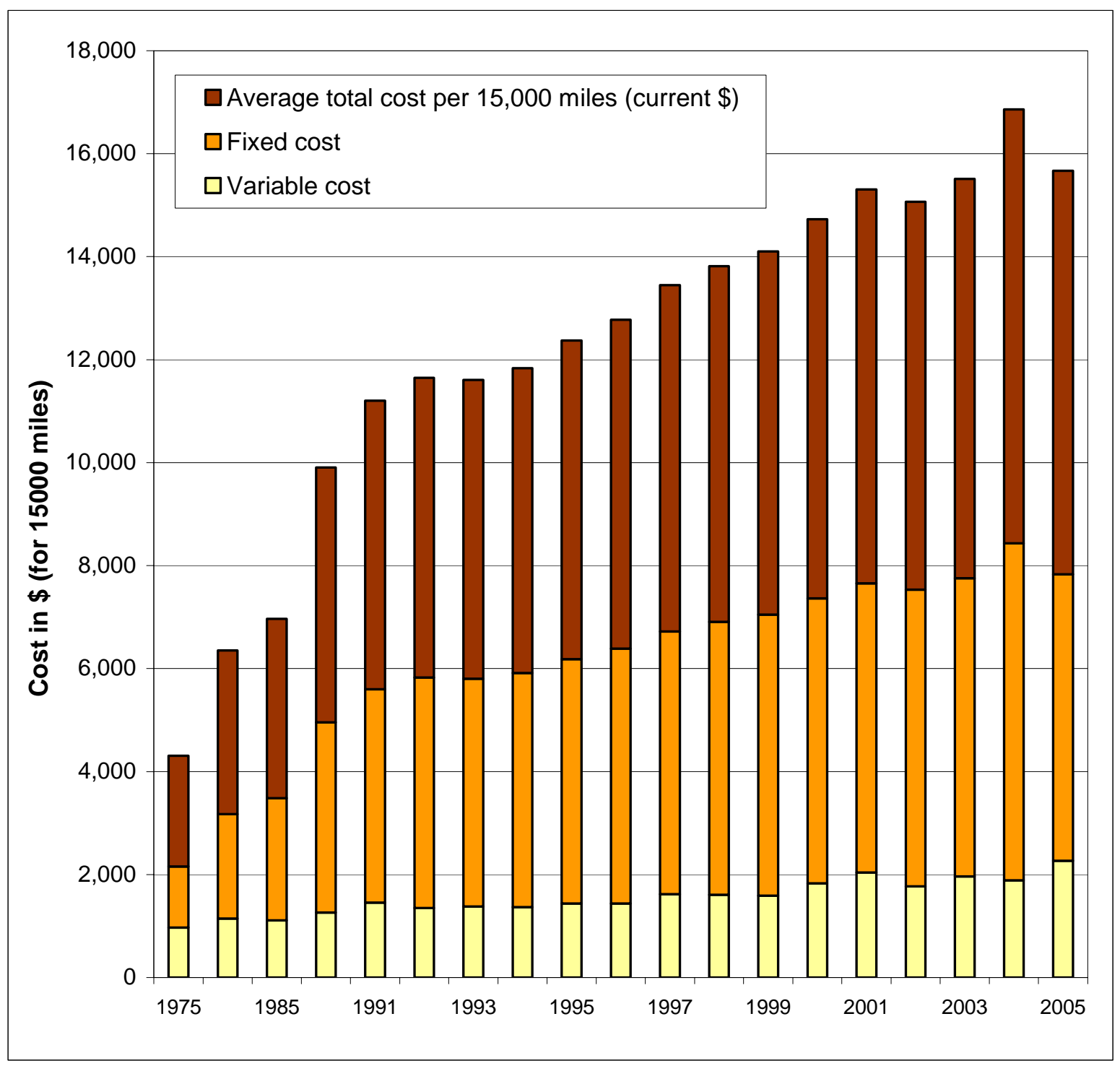

Figure 8 Average Cost of Owning and Operating Private Automobiles

Table 7 shows the detailed expenditure on transportation based on the Bureau of Transportation Statistics, Annual Report, 2006. ${ }^{20}$ There is a small reduction in the expenditures in 2004 compared to the previous two years (about 5\%), which could be accounted for due to the reduction in vehicle purchases during 2004. Figure 9 shows the trend in consumer expenditures for transportation over time. 
Table 7 US Average Transportation Expenditure Growth over Time

\begin{tabular}{|c|c|c|c|c|c|}
\hline Year & $\begin{array}{c}\text { Vehicle } \\
\text { Purchases }\end{array}$ & $\begin{array}{c}\text { Gasoline and } \\
\text { Motor Oil }\end{array}$ & $\begin{array}{c}\text { Other Vehicle } \\
\text { Expenses }\end{array}$ & $\begin{array}{c}\text { Other } \\
\text { Transportation }\end{array}$ & Total \\
\hline 1994 & 2,889 & 1,287 & 1,925 & 437 & 6,538 \\
\hline 1995 & 2,693 & 1,293 & 1,979 & 396 & 6,361 \\
\hline 1996 & 2,820 & 1,310 & 2,025 & 467 & 6,621 \\
\hline 1997 & 2,732 & 1,330 & 2,206 & 421 & 6,689 \\
\hline 1998 & 2,989 & 1,415 & 2,202 & 450 & 7,056 \\
\hline 1999 & 3,320 & 1,349 & 2,262 & 407 & 7,337 \\
\hline 2000 & 3,418 & 1,291 & 2,281 & 427 & 7,417 \\
\hline 2001 & 3,561 & 1,328 & 2,317 & 393 & 7,600 \\
\hline 2002 & 3,663 & 1,366 & 2,370 & 378 & 7,777 \\
\hline 2003 & 3,822 & 1,268 & 2,216 & 363 & 7,669 \\
\hline 2004 & 3,514 & 1,289 & 2,237 & 407 & 7,448 \\
\hline
\end{tabular}

Source: Bureau of Transportation Statistics, Annual Report, 2006.

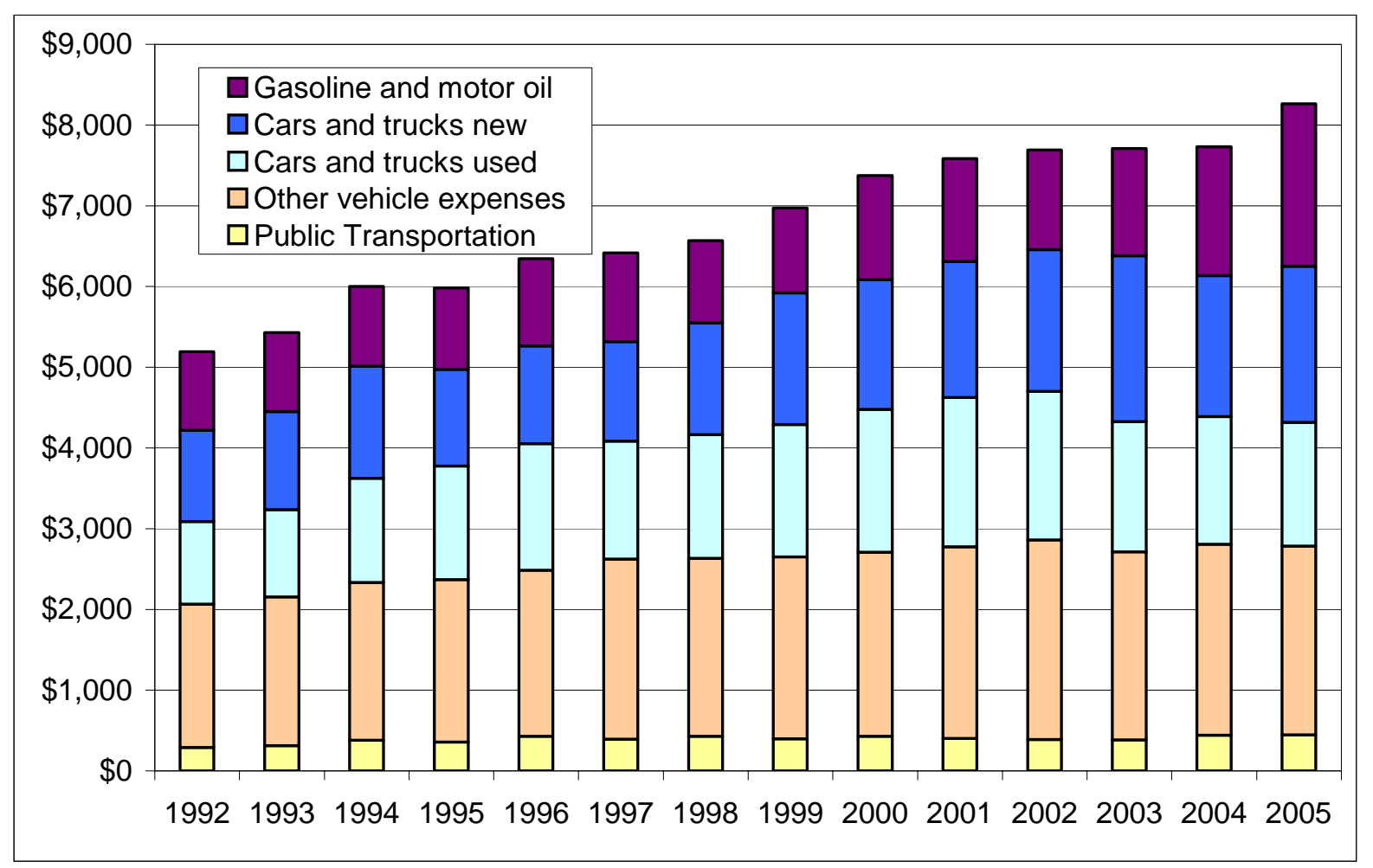

Figure 9 Transportation Expenditures, 1992-2005 


\subsection{Cost Components}

According to various sources, the average price of car is approximately $\$ 25,000$, which is the net vehicle purchase price for a new sedan. The additional costs of the car are taxes, insurance, maintenance costs like oil change, repair etc, and operating costs for fuel, tires etc., each of which will be described below.

Tax and registration - On average, State sales tax comes to about $\$ 2,000$ (8\%) of vehicle cost. Additionally, registration, tag, and emission fees total about \$500 - \$600 (2.5\%).

Insurance - This cost varies with the driving history of the owner and the family. Liability insurance is required to register the vehicle and it takes effect if the owner is judged at fault in a collision. No-fault insurance is mandatory in many states and it covers the health and medical expenses of the owner, the passengers in the vehicle, and any pedestrians who might get injured in an accident. Another common insurance is referred to as comprehensive which covers theft, fire, and damage due to other natural calamities. The collision coverage covers the damages to a vehicle caused by a collision and pays to fix the car even if the driver is judged at fault. Both collision and comprehensive coverage are required if the car is financed. Insurance cost in general can be anywhere between $\$ 50$ and $\$ 500(0.2-2 \%)$ per month.

Fuel - The US Department of Transportation reports that, on average, new vehicles are driven 15,000 miles per year and an average used car (five years old) about 13,500 miles per year. EIA reports the US average retail gasoline prices (regular grade) as of June 25, 2007 , were $\$ 2.98$ per gallon, which results in $\$ 190$ per month for fuel.

Maintenance and Repairs - Maintenance costs form a significant part of the hidden costs of the car depending upon its use and its age. Typically, the maintenance costs per month are about $\$ 50$ for a newer car (less than 5 years and 80,000 miles), and from $\$ 75$ to $\$ 100$ for an older car (more than 5 years and 80,000 miles). The cost of repairs is the estimated cost for all repairs incurred by the vehicle manufacturer/owner for five years from the date of purchase assuming 15,000 miles are driven annually. ${ }^{21}$ 
Depreciation - Depreciation can be calculated as the difference in the vehicle's retail price over a given time period. It is expressed as a percentage. The total depreciation is the total decline in the market value of the car, for the period which it is owned. It is influenced by many factors like the miles put on the vehicle and the condition of the car.

\subsection{National Household Travel Survey (NHTS)}

The NHTS is the source of data on travel behavior. Relative use of modes as a function of household auto availability was derived from NHTS data. The 2001 NHTS is a sample survey of the nation's daily personal travel. It is the only authoritative source of national data on daily trips.

These data were collected for all trips, all modes, all purposes, all trip lengths, and all areas of the country. The 2001 NHTS was conducted during the period from March 2001 through May 2002. Like all large-scale sample surveys, it involved several stages of data collection. First, a stratified random sample of telephone numbers was obtained. Second, the sample of telephone numbers was screened to identify residential households. Third, a member of the household was asked a series of questions about the persons and vehicles of the household. Following this interview, the household was assigned a travel day for trip reporting. Then, travel diaries were prepared and mailed to the household. Following the household's travel day, interviewers called to conduct the person interview for each eligible household member.

Data from the 2001 NHTS are available from the US Department of Transportation in separate files, which are used for this study. These files include the Household File, Person File, and Travel Day File. The Household File contains data on household demographic, socio-economic, and residence location characteristics for 69,817 households. The Person File contains data on personal and household characteristics, attitudes about transportation, and general travel behavior characteristics such as usual modes of transportation to travel to work for 160,758 persons. The Travel Day File contains trip-based data on trip purposes, modes, trip lengths in terms of time and distance, and trip start times for 642,292 trips. Each comprehensive file (all add-ons) has its own weighting variable to expand the sample to provide national estimates in the case of the Household and Person Files, and annualized national estimates in the case of the Travel Day. 


\subsection{American Community Survey (ACS)}

The ACS is the data source for information on current auto availability for US areas. This annual survey administered by the Census Bureau collects a variety of household and personal demographic and economic information used throughout the country as the preeminent socio-demographic data source. For this research it is used to provide data on household auto availability. Figure 10 provides a graphic of the relationship between transit mode share for work trips and household auto ownership. The correlation between these variables is visible from the graphic presentation and was confirmed with a logistic regression that calculated the share of transit use for commuting as a function of mean vehicle availability. This urban area aggregate data provides further confirmation of the relationship between auto availability and transit use.

Mean household auto availability is 1.76 vehicles per household, and the vast majority of metro areas have vehicle availability ranging from about 1.6 to 1.9 per household.

\subsection{Logistic Model}

To understand the variation in household transit use as a function of vehicle availability, the ACS data on commuting transit mode share and mean vehicle availability have been reviewed for major urban areas in the US to determine the aggregate urban area relationships. This was carried out by conducting a logistics regression of the data to derive the relationship. This relationship is used and discussed later in the report as part of the policy analysis. 


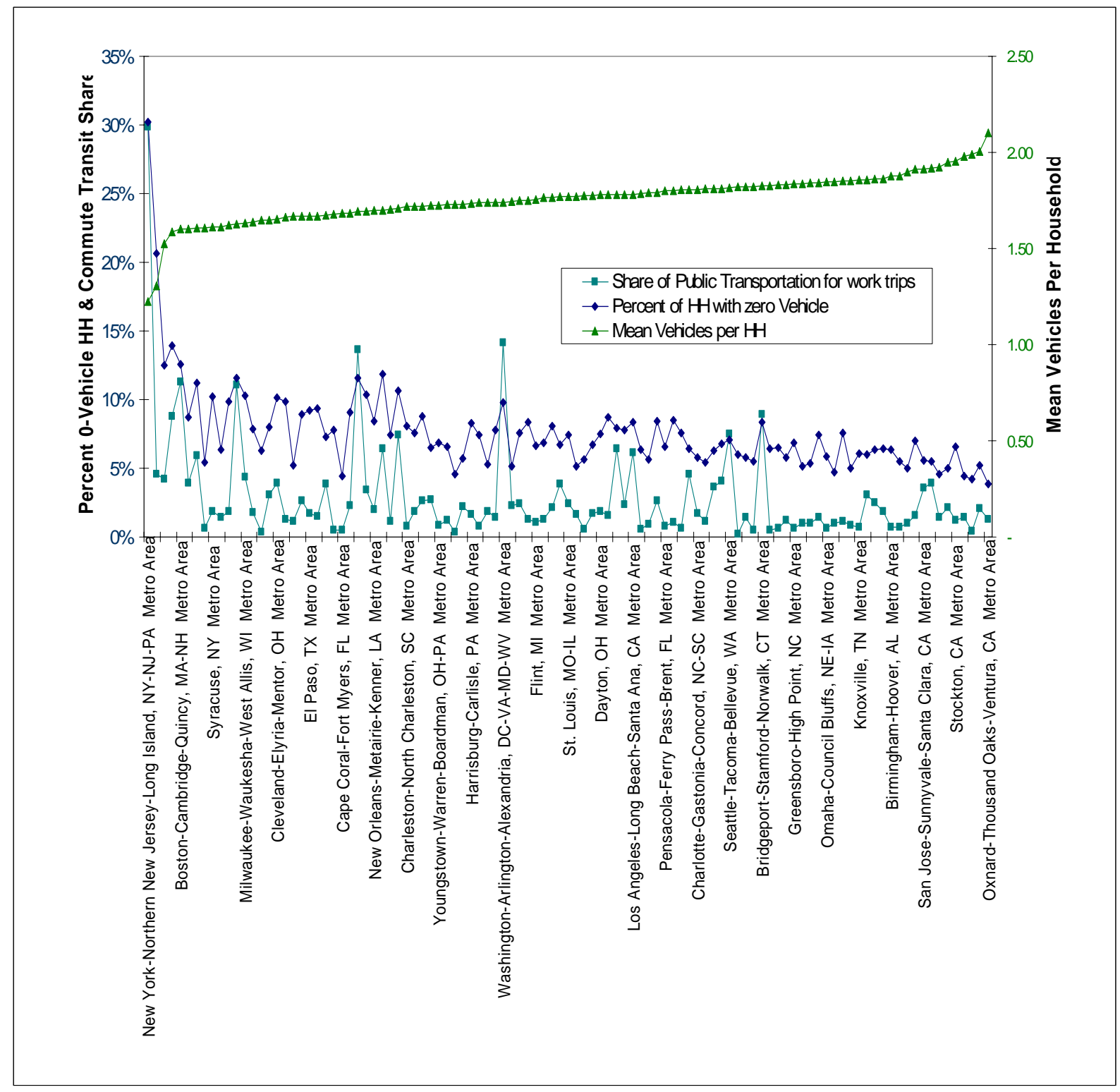

Figure 10 Mean Household Vehicle Availability

Transit Share $(y)=1 /\left[1+e^{\wedge}(-0.145+2.355 *\right.$ mean vehicle availability $\left.)\right]$ Intercept $=0.14506$

Mean $(X)=1.76$

Elasticity $=-4.155$

$X$ Variable $1=-2.35490$

(Elasticity $=$ coefficient ${ }^{*}$ Mean of $\left.X\right)$

This equation produces an approximate 0.44 increase in the percent of commuters who use public transit for each decline in mean household auto ownership of 0.1 vehicles. In terms of elasticity of mode share with respect to mean household vehicle availability the value is 
approximately -0.18 when working within the range of vehicle availability of 1.6 to 1.9. This relationship is subsequently compared with NHTS derived travel behavior changes as a function of vehicle availability at the household level.

\subsection{National Transit Database}

The National Transit Database (NTD) is the Federal Transit Administration's (FTA's) primary national database for statistics on the transit industry. Recipients of FTA Urbanized Area Formula Program (§ 5307) and Nonurbanized Area Formula Program (§ 5311) are required by statute to submit data to the NTD. Over 650 transit agencies and authorities file annual reports to FTA through the internet-based reporting system. Each year, NTD performance data are used to apportion over $\$ 4$ billion of FTA funds to transit agencies in urbanized areas (UZAs). Annual NTD reports are submitted to Congress summarizing transit service and safety data. The NTD is the system through which FTA collects uniform data needed by the Secretary of Transportation to administer department programs. The data consist of selected financial and operating data that describe public transportation characteristics. The NTD data is available to the public and is the primary source of data for policy analysis of the transit industry.

For this research, NTD data is used to understand transit operating costs. 


\section{SCENARIO ANALYSIS TOOL}

To support the analysis carried out as part of this research, an Excel spreadsheet tool was developed. This chapter describes critical sections of the spreadsheet with brief narrative comments explaining its application.

The multi-worksheet spreadsheet starts with a logic flow diagram on the initial page. Subsequent pages process various data items to produce the auto ownership scenarios. Screen captures and narrative of critical pages are included below.

\subsection{Ownership Distribution}

The second page of the spreadsheet (labeled "1. Own Dist" for ownership distribution) allows the user to input study area data. These data could represent a real urban area, a hypothetical area or a sector or corridor in an area. For purposes of the scenario analysis carried out for this project, base data from Hillsborough County, Florida were used. The user inputs information on demographics, transit service mileage, transit spending, and ridership. These data are available from transit agency submittals to the National Transit Database and Census data. The user can also input the distribution of vehicle ownership (what percentage of household have $0,1,2,3$, 4, or 5+ vehicles) for the study area. This information is available annually from the American Community Survey (ACS), a product of the Census. The spreadsheet then calculates the study area household allocation matrix for vehicle ownership and number of adults per household categories. These household composition distribution characteristics (which are not readily available at the local level) are extracted from a 2001 National Household Travel Survey and applied to the study area.

The spreadsheet then calculates a derived study area base vehicle allocation matrix.

This matrix represents the basic conditions in terms of vehicle ownership in the study area before any policy initiatives are implemented to reduce vehicle ownership.

As seen in Figure 11, the research team used judgment to color code the various matrix cells into groups. The four groups are different in terms of impact and feasibility of changing 
vehicle ownership. The yellow cells generally indicate categories of vehicle ownership where there is a surplus of vehicles for adults in the household. Thus, reductions in vehicle ownership in these households may be unlikely to produce mode share changes or VMT reductions as there are sufficient vehicles to accommodate travel even if the household gave up one vehicle.

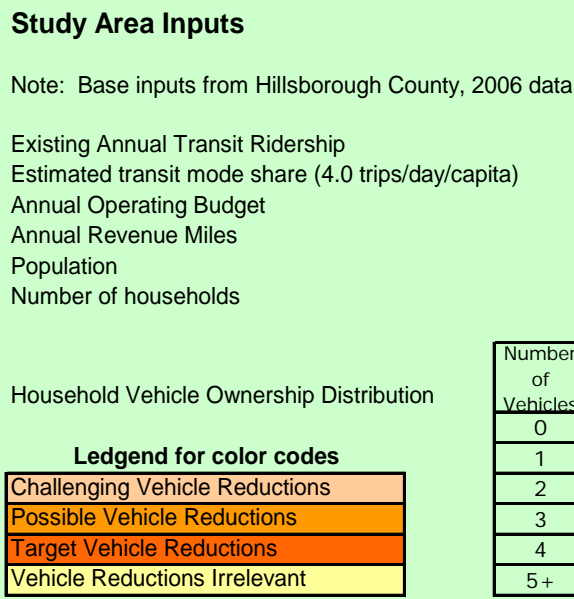

Derived Study Area Household Allocation

\begin{tabular}{|l|r|r|r|r|r|r|}
\hline \multirow{4}{*}{$\begin{array}{c}\text { HH } \\
\text { Vehicles }\end{array}$} & \multicolumn{7}{|c|}{ Number of adults in HH } & \multirow{2}{*}{} \\
\cline { 2 - 7 } & 1 & \multicolumn{1}{|c|}{2} & \multicolumn{1}{c|}{3} & \multicolumn{1}{c|}{4} & $5+$ & \multicolumn{1}{c|}{ All } \\
\hline 0 & 19,788 & 7,234 & 1,327 & 605 & 164 & 29,118 \\
\hline 1 & 114,712 & 56,119 & 6,604 & 1,517 & 309 & 179,261 \\
\hline 2 & 17,578 & 145,929 & 13,308 & 2,513 & 387 & 179,716 \\
\hline 3 & 2,238 & 27,554 & 11,478 & 2,225 & 183 & 43,678 \\
\hline 4 & 801 & 8,086 & 5,021 & 2,610 & 317 & 16,834 \\
\hline $5+$ & 351 & 2,914 & 1,769 & 1,025 & 311 & 6,370 \\
\hline All & 155,468 & 247,836 & 39,507 & 10,494 & 1,671 & 454,976 \\
\hline
\end{tabular}

Figure 11 Auto Ownership Distribution

\section{Derived Study Area Base Vehicle Allocation}

\begin{tabular}{|l|r|r|r|r|r|r|}
\hline \multirow{4}{*}{$\begin{array}{c}H H \\
\text { Vehicles }\end{array}$} & 1 & 2 & 3 & 4 & $5+$ & \multicolumn{1}{|c|}{ All } \\
\cline { 2 - 7 } & & & & & & \\
\hline 0 & 0 & 0 & 0 & 0 & 0 & 0 \\
\hline 1 & 114,712 & 56,119 & 6,604 & 1,517 & 309 & 179,261 \\
\hline 2 & 35,15 & 291,858 & 26,617 & 5,026 & 775 & 359,431 \\
\hline 3 & 6,719 & 82,663 & 34,433 & 6,674 & 548 & 131,033 \\
\hline 4 & 3,203 & 32,343 & 20,084 & 10,441 & 1,267 & 67,336 \\
\hline 5.65363 & 1,982 & 16,473 & 10,003 & 5,794 & 1,760 & 36,012 \\
\hline All & 161,768 & 479,455 & 97,740 & 29,451 & 4,659 & 773,073 \\
\hline
\end{tabular}

Figure 12 Derived Study Area Base Vehicle Allocation Matrix 
The dark orange category is believed to be a reasonable target category for vehicle reduction policies as these households might see some travel behavior changes but would not be aggressively penalized as multiple vehicles would remain to be shared among adult drivers. Individuals may require some temporal shifts in travel activities to preserve their current mode choice and trip making characteristics.

The light orange category is felt to be those households that might be promising targets for vehicle reduction as vehicle reductions would be likely to impact travel and transit use without being too onerous. These households may require some travel behavior changes but would continue to have autos available.

The tan category includes those households where a vehicle reduction would be expected to have a significant change on household travel behavior and/or activity patterns. In many cases, this would imply shifting to zero vehicle categories, a significant implication for many households.

In addition to exploring these data from the perspective of the household impact, it is also useful to understand the share of households in the various categories. Obviously, the overall impact of any policy will be influenced by the share of the population that is influenced by that policy. The largest single category of households is the two-adult twovehicle households followed by the one-adult one-vehicle households. Together, these groups comprise over 50 percent of all households (see Figure 13).

Households Percents

\begin{tabular}{|l|r|r|c|c|c|c|}
\hline \multirow{3}{*}{$\begin{array}{c}\mathrm{HH} \\
\text { Vehicles }\end{array}$} & \multicolumn{6}{|c|}{ National Household Vehicle Ownersip Distribution, 2001} \\
\cline { 2 - 7 } & 1 & \multicolumn{4}{|c|}{ Number of adults in $\mathrm{HH}$} & \multirow{2}{*}{ All } \\
\hline 0 & $5.52 \%$ & $2.02 \%$ & $0.37 \%$ & $0.17 \%$ & $0.05 \%$ & $8.13 \%$ \\
\hline 1 & $20.12 \%$ & $9.84 \%$ & $1.16 \%$ & $0.27 \%$ & $0.05 \%$ & $31.44 \%$ \\
\hline 2 & $3.64 \%$ & $30.24 \%$ & $2.76 \%$ & $0.52 \%$ & $0.08 \%$ & $37.24 \%$ \\
\hline 3 & $0.77 \%$ & $9.43 \%$ & $3.93 \%$ & $0.76 \%$ & $0.06 \%$ & $14.95 \%$ \\
\hline 4 & $0.25 \%$ & $2.57 \%$ & $1.60 \%$ & $0.83 \%$ & $0.10 \%$ & $5.36 \%$ \\
\hline $5+$ & $0.16 \%$ & $1.32 \%$ & $0.80 \%$ & $0.46 \%$ & $0.14 \%$ & $2.88 \%$ \\
\hline All & $30.46 \%$ & $55.43 \%$ & $10.61 \%$ & $3.01 \%$ & $0.48 \%$ & $100.00 \%$ \\
\hline
\end{tabular}

Figure 13 Household Vehicle Ownership Distribution 


\subsection{Vehicle Changes}

The next spreadsheet page labeled "2. Vehicle Changes" is designed to allow the analyst to input assumed vehicle ownership changes. This is then used to create scenarios of lower household vehicle ownership. This research has not explored the types of financial or policy initiatives that would be required to impact vehicle ownership at the levels tested. That information, while critical to the ultimate success of such initiatives, is not well understood due to the lack of policy initiatives in this area.

The spreadsheet enables the analysts to alter vehicle ownership for each cell of the matrix, as defined by the number of adults in the household and the number of household vehicles. Using the input vehicle change information, the spreadsheet calculates changes in vehicle ownership. It is important to remember that the percent change input into the spreadsheet refers to the share of households in each category giving up one vehicle. Thus, the overall distribution of vehicle ownership is influenced as households shift between categories.

This sheet produces two sets of outputs (Figure 14), the first being a summary table that presents the consequences of the vehicle ownership reductions as well as several other summary statistics, some taken from subsequent pages in the spreadsheet. A second summary table portrays the change in household vehicle ownership.

\begin{tabular}{|l|r|}
\hline Base Vehicles & 773,073 \\
\hline Revised Vehicles & 741,134 \\
\hline Percent change in vehicles owned & $-4.13 \%$ \\
\hline Households & 454,976 \\
\hline Households Impacted & 31,939 \\
\hline$\%$ Households Impacted & $7.02 \%$ \\
\hline \% Original Car Owning Households Impacte & $-7.50 \%$ \\
\hline New transit trips & $11,856,066$ \\
\hline New annual transit trips/relinquished vehicle & 371 \\
\hline Percent change in HH spending for vehicles & $-3.65 \%$ \\
\hline Household savings per relenquished vehicle & $\$ 3,457$ \\
\hline Base mean vehicle ownership per HH & 1.70 \\
\hline Revised mean vehicle ownership per HH & 1.63 \\
\hline
\end{tabular}

\begin{tabular}{|c|r|r|}
\hline \multicolumn{3}{|c|}{ Household Vehicle Distribution } \\
\hline $\begin{array}{l}\text { Number of } \\
\text { Vehicles }\end{array}$ & $\begin{array}{c}\text { Original \% of } \\
\text { Households }\end{array}$ & $\begin{array}{c}\text { Revised \% of } \\
\text { Households }\end{array}$ \\
\hline 0 & $6.4 \%$ & $9.4 \%$ \\
\hline 1 & $39.4 \%$ & $39.4 \%$ \\
\hline 2 & $39.5 \%$ & $37.3 \%$ \\
\hline 3 & $9.6 \%$ & $9.2 \%$ \\
\hline 4 & $3.7 \%$ & $3.5 \%$ \\
\hline $5+$ & $1.4 \%$ & $1.3 \%$ \\
\hline
\end{tabular}

Figure 14 Household Vehicle Distribution 


\subsection{Household Savings}

The third spreadsheet page calculates the household expenditure savings associated with vehicle ownership. The database to support this page was developed through analysis of the consumer expenditure survey data. This data, collected by the US Department of Commerce, is based on a quarterly survey process that has been underway nationally and in major metropolitan areas for a number of years. The survey gauges all household spending activity into numerous categories including several categories for expenditures on transportation. This comprehensive survey is a national standard for household transportation spending. The data used in the spreadsheet represent national average data from the 2006 survey. The spending is intended to represent all spending associated with ownership, operation, and maintenance of a personal vehicle including rental vehicles, parking, and associated costs. It does not include indirect costs of vehicle ownership such as owning and maintaining a garage, nor does it value the owner's time spent in owning and using a vehicle.

The spending reported in the survey represents actual consumer expenditures and hence, is different than some of the frequently reported auto ownership cost analyses that are based on owning a new midsize car for a three-year period and operating a given number of miles per year. Instead, this database is intended to reflect the actual cost of ownership that might include everything from a young adult with a hand-me-down 15-year-old car that they maintain in the driveway to someone leasing an expensive luxury sedan. That data is shown in Figure 15.

\begin{tabular}{|c|c|c|c|c|c|c|}
\hline \multicolumn{7}{|c|}{ Spending on Vehicle Travel (from Consumer Expenditure Survey Data) } \\
\hline \multirow{3}{*}{$\begin{array}{c}\mathrm{HH} \\
\text { Vehicles }\end{array}$} & \multicolumn{6}{|c|}{ Derived Study Area Household Allocation } \\
\hline & \multicolumn{5}{|c|}{ Number of adults in $\mathrm{HH}$} & \multirow[b]{2}{*}{ All } \\
\hline & 1 & \begin{tabular}{l|l}
2 & \\
\end{tabular} & 3 & 4 & $5+$ & \\
\hline 0 & $\$ 355$ & $\$ 847$ & $\$ 743$ & $\$ 764$ & $\$ 680$ & \\
\hline 1 & $\$ 3,102$ & $\$ 3,748$ & $\$ 3,832$ & $\$ 3,949$ & $\$ 5,481$ & \\
\hline 2 & $\$ 9,972$ & $\$ 7,289$ & $\$ 7,723$ & $\$ 7,411$ & $\$ 7,198$ & \\
\hline 3 & $\$ 10,891$ & $\$ 15,826$ & $\$ 11,084$ & $\$ 10,976$ & $\$ 10,481$ & \\
\hline 4 & $\$ 10,862$ & $\$ 17,470$ & $\$ 19,057$ & $\$ 15,078$ & $\$ 14,307$ & \\
\hline $5+$ & $\$ 11,208$ & $\$ 20,001$ & $\$ 25,726$ & $\$ 26,729$ & $\$ 29,324$ & \\
\hline All & & & & & & \\
\hline
\end{tabular}

Figure 15 Household Expenditure on Travel by Ownership Vehicle Distribution 
The data table is used as the basis for estimating household savings associated with foregoing one of the household vehicles. In general, the data suggest that the marginal savings of foregoing a vehicle is approximately $\$ 3,500$. Interestingly, the highest marginal cost vehicle ownership situations appear to be in those situations where vehicle ownership exceeds the number of adults in the household by one vehicle. We have speculated that this indicates situations where an extra vehicle is something of a household luxury, perhaps a specialized vehicle (recreational vehicle, sports car, or collector vehicle) and, hence its marginal cost may be higher. Household savings per relinquished vehicle is shown in Figure 16.

\begin{tabular}{|c|r|r|r|r|r|r|}
\hline \multicolumn{7}{|c|}{ Savings per Relinquished Vehicle } \\
\hline \multirow{2}{*}{$\begin{array}{c}H H \\
\text { Vehicles }\end{array}$} & \multicolumn{7}{|c|}{ Number of adults in $\mathrm{HH}$} & \multirow{2}{*}{ All } \\
\cline { 2 - 6 } & 1 & 2 & 3 & 4 & \multicolumn{1}{|l|}{$5+$} & \\
\hline 0 & $\$ 0$ & $\$ 0$ & $\$ 0$ & $\$ 0$ & $\$ 0$ & \\
\hline 1 & $\$ 2,747$ & $\$ 2,901$ & $\$ 3,089$ & $\$ 3,185$ & $\$ 4,801$ & \\
\hline 2 & $\$ 6,870$ & $\$ 3,540$ & $\$ 3,892$ & $\$ 3,462$ & $\$ 1,717$ & \\
\hline 3 & $\$ 919$ & $\$ 8,537$ & $\$ 3,361$ & $\$ 3,565$ & $\$ 3,283$ & \\
\hline 4 & $-\$ 29$ & $\$ 1,644$ & $\$ 7,973$ & $\$ 4,101$ & $\$ 3,827$ & \\
\hline $5+$ & $\$ 346$ & $\$ 2,531$ & $\$ 6,669$ & $\$ 11,651$ & $\$ 15,016$ & \\
\hline All & & & & & & \\
\hline
\end{tabular}

Figure 16 Household Savings by Ownership Vehicle Distribution

We feel confident that these numbers provide a very reasonable basis for estimating household cost savings associated with vehicle reduction policies. However, there is no actual experience or real data that reflects how households would behave if various initiatives or incentives were put in place to reduce vehicle ownership. At the personal level it is not clear which vehicle or vehicles households would give up when downsizing their fleet. One presumes that they would retain vehicles that are both more reliable (newer) and more flexible, thus giving up older and perhaps niche use vehicles.

Some slight irregularities in the uniformity of the values as one moves across the matrix are an artifact of the small sample sizes for some of the fringe cells in the data table. It is not believed that these few seemingly illogical values will influence the research findings.

An interesting observation when reviewing the data is that even households with zero vehicles have vehicle expenses. This might include rental vehicles, paying gas money or parking for someone providing a ride, retaining a driver's license or related costs. It is to be 
noted that the fees for taxi services are not reported as part of vehicle expenditures but rather as part of public transportation spending. Thus, even becoming a zero car household does not remove all of the costs of vehicle transportation from the household budget. For other households, reducing the ownership by one vehicle would be expected to result in additional travel on the remaining household vehicles. The spreadsheet is designed to allow the user to input a marginal mileage costs for additional travel on remaining vehicles to be debited from savings from relinquishing vehicles. An estimate of the changes in travel behavior calculated on the subsequent spreadsheet page is used to estimate the mileage shifted to other household vehicles. For purposes of this analysis, a marginal mileage cost of $\$ 0.20$ per mile was used but this can be altered by the analyst in scenario development.

\subsection{Household Travel Changes}

The fundamental logic used to represent the changes in travel behavior for households giving up vehicles was to assume that the overall mobility remained the same (i.e., their trip making remained constant) but that their mode use behaviors shifted to that of the group that they moved into by virtue of the fact that they relinquished a vehicle. The basis for travel behavior used in this analysis was derived by processing the 2001 National Household Travel Survey to obtain trip making and mode use behaviors for the respective household categories used in the analysis. Figures 17 and 18 present that national data.

Data from 2001 NHTS

\begin{tabular}{c|c|c|c|c|c|c}
\hline \multirow{2}{*}{ Household Annual Person Trip Rates } \\
\cline { 2 - 7 } HH & \multicolumn{7}{|c|}{ Number of adults in HH } & \\
\cline { 2 - 7 } Vehicles & 1 & 2 & 3 & 4 & $5+$ & \\
\hline 0 & 1,014 & 2,808 & 4,000 & 4,343 & 4,469 & \\
\hline 1 & 1,672 & 3,584 & 4,923 & 5,565 & 7,234 & \\
\hline 2 & 2,046 & 4,597 & 5,325 & 5,787 & 6,844 & \\
\hline 3 & 2,172 & 4,846 & 5,938 & 6,295 & 9,596 & \\
\hline 4 & 2,088 & 5,021 & 6,626 & 7,313 & 8,863 & \\
\hline $5+$ & 1,935 & 4,980 & 6,524 & 7,103 & 9,689 & \\
\hline & & & & & &
\end{tabular}

Figure 17 Household Annual Person Trip Rates 
Data from 2001 NHTS

Travel Behavior Analysis

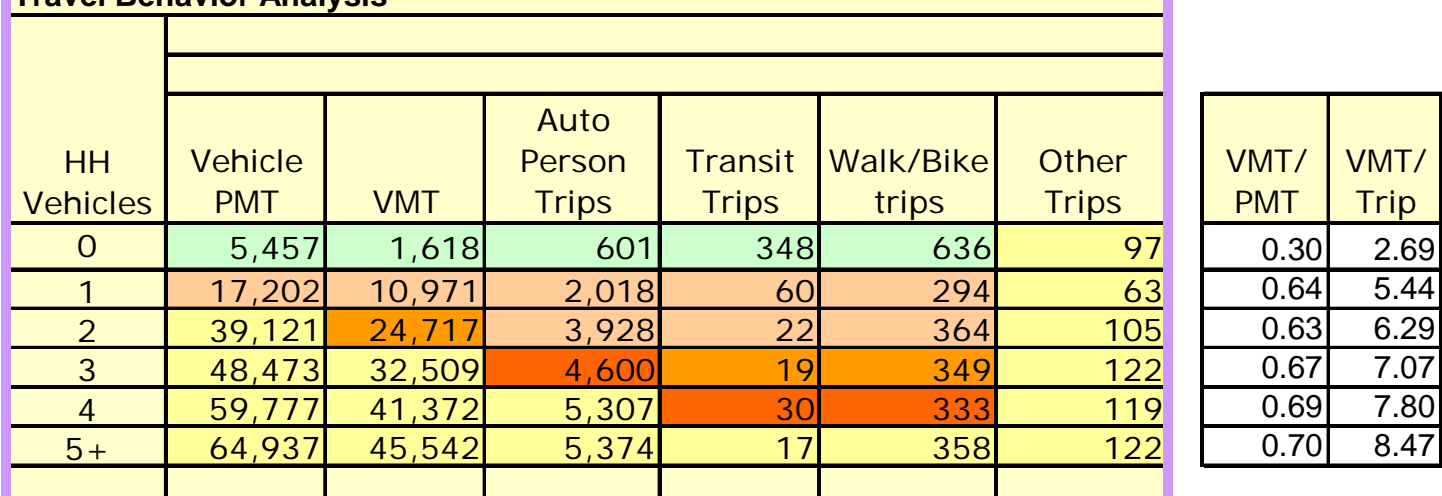

Figure 18 Household Travel Behavior Analysis

The spreadsheet is used to develop an estimate of trips diverted to transit based on the shifts of behaviors for households relinquishing a vehicle. Figure 19 outlines the shifts per household in each category relinquishing a vehicle.

\begin{tabular}{|c|r|r|r|r|r|r|}
\hline Trips to Transit per household relinquishing vehicle \\
\hline \multirow{2}{*}{$\begin{array}{c}\mathrm{HH} \\
\text { Vehicles }\end{array}$} & \multicolumn{7}{|c|}{ Number of adults in HH } & \multirow{2}{*}{ All } \\
\cline { 2 - 7 } & 1 & 2 & 3 & 4 & $5+$ & \\
\hline 0 & & & & & & 4,184 \\
\hline 1 & 304 & 653 & 896 & 1,013 & 1,317 & 486 \\
\hline 2 & 40 & 91 & 105 & 114 & 135 & 34 \\
\hline 3 & 3 & 6 & 7 & 7 & 11 & -44 \\
\hline 4 & -3 & -7 & -10 & -11 & -13 & 72 \\
\hline $5+$ & 5 & 12 & 16 & 17 & 23 & 4,733 \\
\hline All & 349 & 754 & 1,015 & 1,141 & 1,474 & 4 \\
\hline
\end{tabular}

Figure 19 Transit Trips for Households with Relinquished Vehicle

The negative numbers represent anomalies associated with the small sample sizes and collapsing groups with more than five vehicles. Most striking in the table is the fact that 88 percent of the increase in transit trips would be from those households that shifted into the zero vehicle categories. Given the travel behavior revealed in the NHTS and the methodology assumptions of this work, it becomes clear that the greatest transit ridership impact would occur for initiatives that were successful in creating zero-car households. 


\subsection{Transit Cost}

The next spreadsheet page is used to calculate the transit implications of the vehicle ownership change scenario. The page is set up to allow the analyst to specify several assumptions in the development of the scenario.

\section{Savings Capture/Reinvestment Assumption}

The top section of the page allows the analyst to specify the share of estimated savings from relinquishing vehicles that might be able to be recaptured for reinvestment in transit service. A premise underlying this research and a presumption in many discussions of how different development and pricing structures could influence auto ownership and mode use is that one of the benefits of more intensive urban development patterns is that they would favor greater transit use and enable lower auto ownership. Thus, the presumption is that at least some of the public savings from lower auto ownership could be captured in some manner in order to have additional resources available for support of public transit. This research does not presume to discern the extent to which public attitudes would support revenue increases to support transit. What it does do is help establish a relationship between the potential savings by those that relinquish vehicles and the public cost of providing transit services to meet estimates of enhanced demand. It thus provides a perspective on the overall economic consequences of such a change. It is understood that the savings from vehicle reductions would be received by the households relinquishing vehicles but that in all probability any additional revenues raised to support transit would come from a combination of fares and taxes most probably paid by the general public, including those persons who did not relinquish vehicles or necessarily directly benefit from improved transit services.

The slider feature on the top of the spreadsheet page allows the analyst preparing the scenario to alter the share of relinquished vehicle savings that are captured (regardless of the mechanism or actual source of additional revenues) and reinvested in additional transit services. The slider allows the analyst to specify the percentage from 0 to 100 percent. It should be understood that, if there is a program to relinquish vehicles that is successful, it will inevitably require some type of additional transit revenues to enable a quality and capacity of service sufficient to accommodate the new demand. 
The analyst next has to specify the operating cost for service expansion. This can be done either of two ways. The costs for the study area can be used based on the study areas' inputs entered on sheet one of the spreadsheet. This includes a total for revenue miles of service and a total for operating costs which can be used to calculate an average per mile costs. Alternatively, the analyst can use the slider provided to specify an operating cost in terms of the percentage of the distribution of operating costs for US transit properties. This distribution is embedded in the spreadsheet and was derived from NTD data for 2005.

In both cases, the analyst can specify a capital adjustment which serves to increase the unit cost of service by a factor to reflect the resources required to provide sufficient capital infrastructure to expand service. For meaningful increases in transit capacity, it will require additional infrastructure and hence a realistic financial plan will require both capital and operating resources. The analyst can input the adjustment factor based on local needs. A historical review of the relationship between the capital and operating budget for similar transit properties over time should provide a reasonable estimate of required capital.

In the spreadsheet, new revenues to support transit services come from three sources: 1 ) revenues captured from relinquished vehicle savings, 2) fare revenues associated with the increase in ridership from the households that relinquished vehicles, and 3) fare revenues associated with the new riders that are attracted due to service improvements (service expansion elasticity). Fare revenues associated with the new riders that are attracted due to service improvements are estimated by first estimating the service improvements attributable to the above mentioned new revenue sources and then applying a service elasticity factor to reflect the probability of additional ridership by persons attracted to the service as a result of the service improvements. To calculate this estimate, an additional spreadsheet variable is included to allow the analyst to specify the service expansion elasticity that they feel is appropriate for the study context. Various literature documents experiences of transit properties in terms of service expansion elasticity. TCRP Report 95 provides perhaps the most comprehensive review. Due to the cyclical nature of service levels, ridership, and fare revenues, the additional revenues from those passengers attracted due to the improved service from spending the fares of elasticity attracted passengers are not captured in the estimate, providing a somewhat conservative financial estimate. Figure 20 shows this section of the spreadsheet. 


\section{Transit Cost \& Quantity}

\section{Share of Auto Reduction Savings Invested in Transit}

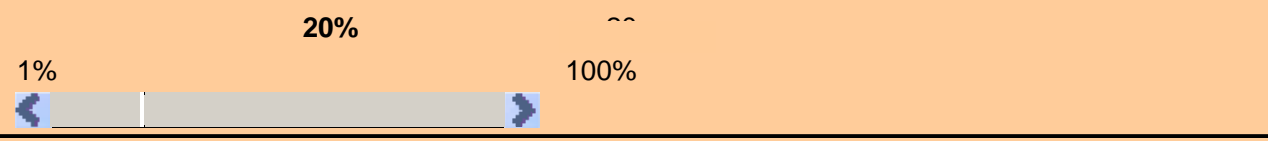

\section{Transit Cost \& Service}

Check Only One

Specific Site Cost

$\square$

Percentile Cost Scenario

OK

Revenue Miles

$8,299,402$

$1 \%$

Operating Budget

$\$ 51,507,790$

Capital Factor

$10 \%$

Cap \& Op Cost/Mile

Service Unit Cost

$\$ 6.83$

Total New Investment

$\$ 28,638,492$

Captured car ownership savings

$\$ 20,339,246$

Fares from shifted households

$\$ 7,507,945$

Fares from service elasticity shifts

$\$ 791,301$

New Annual Revenue Miles

$4,079,083$

Captured car ownership savings

$2,979,312$

Fares from shifted households

$1,099,771$

Fares from service elasticity shifts

not included

Percent Increase in Service

$49.1 \%$

Ridership

Original

$11,500,000$

From Auto Ownership Decline

$10,725,636$

From Service Elasticity

Elasticity

$20 \%$

20

$0 \%$

$7^{100 \%}$

Total Ridership

$1,130,430$

$23,356,066$

Percent Increase in Ridership

$103.1 \%$

Trips/Mi Original

1.39

Trips/Mi New

1.89

Trips/Capita Original

10.07

Trips/Capita New

20.45

Figure 20 Transit Cost and Quantity Slider Tool 


\section{Scenario}

The sixth spreadsheet page is included to allow the analyst to paste scenario results and provide graphical analysis. As such it is not interactive with the other pages. The user can format and add any graphics they desire. The next chapter of this report presents scenario results and provides some observations. 


\section{SCENARIO OBSERVATIONS}

This chapter presents the results of several scenarios that analyze the implications of household vehicle reductions. The spreadsheet tool produces linear relationships so a few data points for each specification of conditions allows the user to understand the relationships. Base conditions are input for Hillsborough County for purposes of exemplifying the role of the tool. Basic input assumptions are shown in Figure 21.

\begin{tabular}{l} 
Study Area Inputs \\
Note: Base inputs from Hillsborough County, 2006 data \\
\cline { 2 - 2 } Existing Annual Transit Ridership \\
Estimated transit mode share (4.0 trips/day/capita) \\
Annual Operating Budget \\
Annual Revenue Miles \\
Population \\
Number of households
\end{tabular}

Figure 21 Study Area Inputs

The transit cost assumptions and the assumptions regarding reinvestment are shown in the following screen capture, Figure 22. 


\section{Transit Cost \& Quantity}

Share of Auto Reduction Savings Invested in Transit

$25 \%$

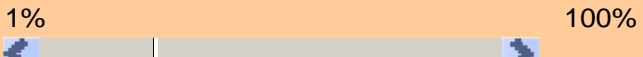

$+\quad$ o $100 \%$

Transit Cost \& Service

Check Only One

Specific Site Cost

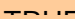

Revenue Miles

$8,299,402$

Operating Budget

$\$ 51,507,790$

Capital Factor

Cap \& Op Cost/Mile

$10 \%$

$\$ 6.83$

Service villi uos

Total New Investment

Captured car ownership savings

Fares from shifted households

Fares from service elasticity shifts

New Annual Revenue Miles

Captured car ownership savings

Fares from shifted households

Fares from service elasticity shifts

Percent Increase in Service

\section{Ridership}

Original

From Auto Ownership Decline

From Service Elasticity

Elasticity ity

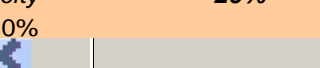

$$
\text { Total Ridership }
$$

Percent Increase in Ridership

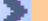

$23,562,479$

Trips/Mi Original

Trips/Mi New

Trips/Capita Original

Trips/Capita New

Estimated increase in Mode Share
$1,336,843$

$104.9 \%$

1.39

1.80

10.07

20.63

867,792

$\$ 7,507,945$

$4,823,912$

$3,724,140$

$1,099,771$

$58.1 \%$

$11,500,000$

$10,725,636$

20

$0.72 \%$

\section{Percentile Cost Scenario $\quad \square \quad$ OK} -...-

$\perp \cup \cup \%$

$\perp \%$

$+$

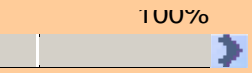

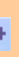

Figure 22 Transit Cost And Quantity 
The results are shown in Figure 23 and Figure 24. The changes in basic output metrics for the scenario with a 7.5 percent of auto owning households giving up a vehicle are shown first.

\begin{tabular}{|l|r|}
\hline Base Vehicles & 773,073 \\
\hline Revised Vehicles & 741,134 \\
\hline Percent change in vehicles owned & $-4.13 \%$ \\
\hline Households & 454,976 \\
\hline Households Impacted & 31,939 \\
\hline$\%$ Households Impacted & $7.02 \%$ \\
\hline$\%$ Original Car Owning Households Impacte & $7.50 \%$ \\
\hline New transit trips & $12,062,479$ \\
\hline New annual transit trips/relinquished vehicle & 378 \\
\hline Percent change in HH spending for vehicles & $-3.65 \%$ \\
\hline Household savings per relenquished vehicle & $\$ 3,457$ \\
\hline Base mean vehicle ownership per HH & 1.70 \\
\hline Revised mean vehicle ownership per HH & 1.63 \\
\hline
\end{tabular}

\begin{tabular}{|c|r|r|}
\hline \multicolumn{3}{|c|}{ Household Vehicle Distribution } \\
\hline $\begin{array}{l}\text { Number of } \\
\text { Vehicles }\end{array}$ & $\begin{array}{c}\text { Original \% of } \\
\text { Households }\end{array}$ & $\begin{array}{c}\text { Revised \% of } \\
\text { Households }\end{array}$ \\
\hline 0 & $6.4 \%$ & $9.4 \%$ \\
\hline 1 & $39.4 \%$ & $39.4 \%$ \\
\hline 2 & $39.5 \%$ & $37.3 \%$ \\
\hline 3 & $9.6 \%$ & $9.2 \%$ \\
\hline 4 & $3.7 \%$ & $3.5 \%$ \\
\hline $5+$ & $1.4 \%$ & $1.3 \%$ \\
\hline
\end{tabular}

Figure 23 Output Matrix From Transit Tool

\begin{tabular}{|c|r|r|r|r|r|r|}
\hline Trips to Trans it per hous ehold relinquishing vehicle \\
\hline \multirow{2}{*}{$\begin{array}{c}\text { HH } \\
\text { Vehicles }\end{array}$} & \multicolumn{7}{|c|}{ Num ber of adults in HH } & \multirow{2}{*}{ All } \\
\cline { 2 - 7 } & 1 & 2 & 3 & 4 & $5+$ & \\
\hline 0 & & & & & & 4,184 \\
\hline 1 & 304 & 653 & 896 & 1,013 & 1,317 & 48 \\
\hline 2 & 40 & 91 & 105 & 114 & 135 & 48 \\
\hline 3 & 3 & 6 & 7 & 7 & 11 & 34 \\
\hline 4 & -3 & -7 & -10 & -11 & -13 & -44 \\
\hline $5+$ & 5 & 12 & 16 & 17 & 23 & 72 \\
\hline All & 349 & 754 & 1,015 & 1,141 & 1,474 & 4,733 \\
\hline
\end{tabular}

Figure 24 Changes in Vehicle Ownership Affecting Transit Travel

Several observations can be noted. The reduction in the number of vehicles is less in percentage terms than the 7.5 percent number due to several factors including the fact that there are some zero auto households and it is assumed each affected household relinquishes one (not all) of their vehicles. Thus, the actual reduction in vehicle population is only 4.13 percent. 
The percent of impacted households is also less than 7.5 percent due to the fact that zerocar households are not impacted. Thus, only 7.02 percent of households are impacted. The percentage change in household spending for vehicles is -3.65 percent. It does not decline as much as the vehicle population due to three facts: persons who shift into zero vehicle households still have vehicle costs, the marginal savings from vehicle reductions is indicated to be less than the average as lower cost/value vehicles are likely to be shed, and trips diverted to existing vehicles will result in higher operating costs on average for the remaining vehicles.

Transit trips per household that relinquishes a vehicle average 378. In closer review of the components of transit ridership growth, approximately 350 additional trips per relinquished vehicle household are a result of relinquishing the vehicle. The additional trips per household result from the induced transit trips attracted by the service expansion supported by capturing vehicle savings and new fare revenues and then investing these new revenues in service expansion. Figure 24 shows the trips to transit per household relinquishing a vehicle.

The travel behavior data derived from NHTS data suggest that the vast majority of the additional transit trips are a result of the dramatic increase in transit trips by households that shift from one to zero vehicles per household. Approximately 88 percent of the new transit trips can be attributed to new 0 -vehicle households. This has very significant policy implications. For policies targeting vehicle ownership reductions as a strategy to grow transit use, success will require either a different response in terms of household travel behavior changes across household vehicle ownership levels than exists today as indicated in the NHTS data, or the policy would need to produce additional zero vehicle households whose travel behavior in terms of mode choice (not trip rates) changes to match those of existing zero vehicle households. Absent that change, the policy implication is that greater transit use is most probable if policies are able to produce more zero-vehicle households. Note that, during the exploration of travel behavior, the research team explored differential behavior across income levels for zero income households to see if transit use varied as a function of income and if higher income levels would produce fewer than average per capita transit trips. Contrary to initial expectations, higher income zero-vehicle households actually had significantly higher per household transit use than the zero-vehicle household average. 
The actual behavioral response to vehicle reductions is likely to be partially dependent on the nature of the mechanism(s) used to produce the lower auto ownership levels.

Presuming it is auto pricing and transit service quality induced changes rather than prescriptive requirements; it is more likely that behavior responses will be more similar to those observed in the NHTS data set. More radical initiatives that limit consumer choice might produce a different travel behavior response. Figure 25 shows scenario 1 results.
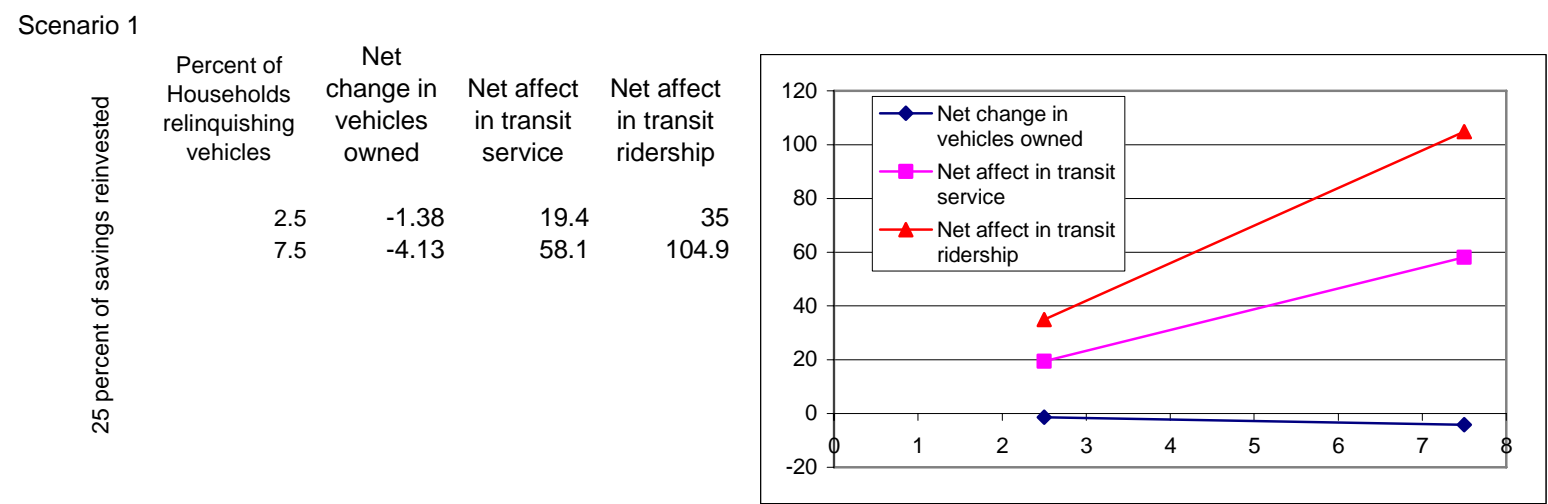

\section{Figure 25 Transit Ridership with 2.5 and 7.5 Percent Reduction in Household Vehicles}

The initial set of scenario assumptions do not produce sufficient revenues to allow transit to expand sufficiently to keep pace with growing demand. While policy initiatives to encourage transit use may result in some improvements in productivity and available excess capacity might accommodate some growth in demand, larger increases in demand associated with higher auto relinquishing rates are not likely to be able to be accommodated without approximately similar increases in service (a 100\% increase in ridership is likely to require nearly a $100 \%$ increase in transit service supply). Thus, the level of reinvestment in transit service will need to be equivalent to a larger share of captured household savings associated with relinquishing vehicles.

Scenario 2 tests such a higher increase to examine what might be closer to equilibrium. At a basic level one can estimate the required new resources based on the new trips per relinquished vehicle number. If each household relinquishing a vehicle produces $350+$ new transit trips annually and each household saves on average $\$ 3,457$, and each transit trip costs on average over $\$ 5$ in additional subsidy to cover operating and incremental capital subsidy, then over half the auto savings will need to be captured in some manner to provide 
adequate resources to support service expansion. A review of the 2001-2005 NTD national profiles indicated that total capital spending on transit expressed as a percentage of total operating cost spending, ranged from 54 to 41 percent and averaged 50 percent. Agency average reported operating cost per trip ranged from $\$ 2.50$ to $\$ 7.94$ in 2005 and averaged \$5.71. Fare revenues averaged approximately $\$ 1.05$ per trip in 2005.

An alternative perspective on transit service expansion is to think of the service level expansion that might be required to attract the increase in ridership implied by the rates of ridership increases associated with lower vehicle ownership levels. Using a service elasticity of approximately 0.4 , a 100 percent increase in ridership would imply a service expansion of 250 percent. Funding this level of service expansion would require more revenues than the total of relinquished vehicle savings associated with that magnitude of change in transit use. This suggests that service expansion alone (with the hope that this will induce vehicle reductions) is unlikely to be a sufficient basis for influencing transit use to enable a self supporting scenario. Farther initiatives to encourage or require transit use increases and/or vehicle relinquishing would be required to produce the scenarios tested.

Scenario 2 as shown in Figure 26 differs only in the assumed share of relinquished vehicle savings capture for reinvestment in transit.
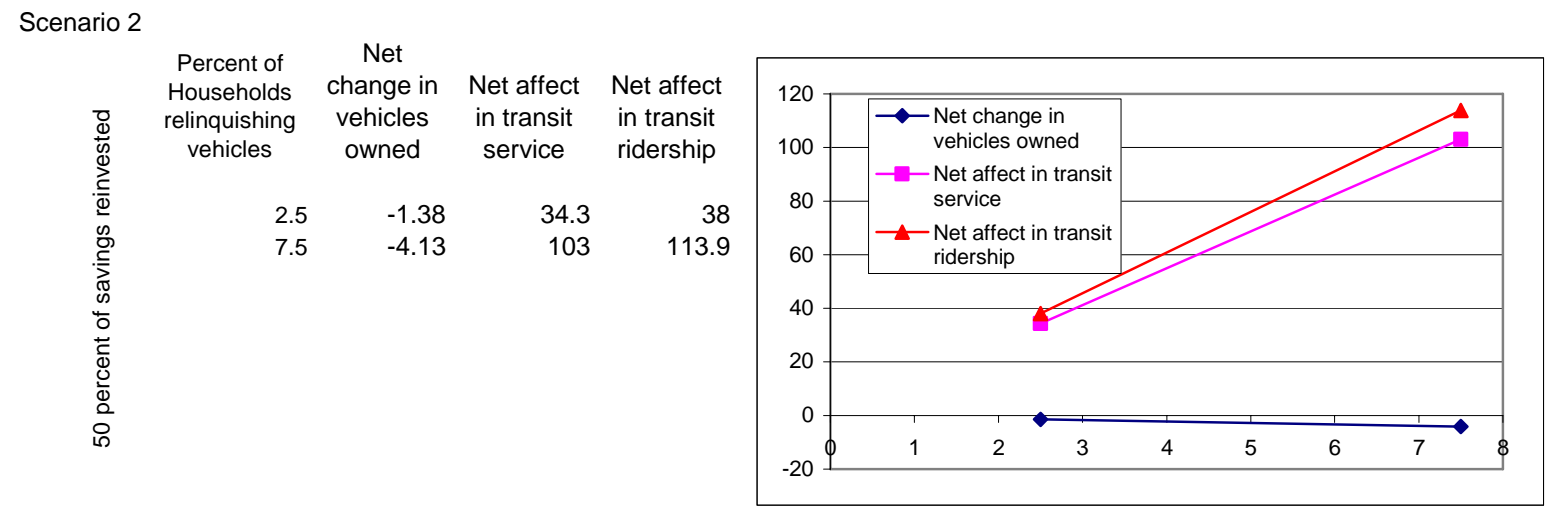
Figure 26 Transit Ridership with 2.5 and 7.5 Percent Reduction in Household
Vehicles

This scenario seems more logical in that service supply more closely tracks ridership increases. While there is not a formal way to determine adequacy of service capacity, it is expected that sustainable service will require service growth to track ridership growth for 
meaningful changes in ridership. Available capacity on existing services might enable some increases in demand to be absorbed, but it is highly unlikely that new demands could produce dramatic improvements in efficiency as geographical and temporal allocations of demand are not likely to be such that new demand will disproportionately fill in excess capacity. In practical terms, this means growth in demand is likely to occur in peak periods and in peak directions and at the most attractive transit service locations in proportion to the growth in demand. Unfortunately, no policy initiatives are likely to only produce demand growth in the off-peak periods and in off-peak directions. While overall service efficiency might increase with a higher propensity to use transit, supply and demand balances will need to be kept in approximate sync.

The Scenario 3 model run was specified to produce a 0.1 reduction in the average household mean auto ownership, as noted in Figure 27. Reinvestment of savings was set at 50 percent and a 50 percent capital cost increment was assessed on transit average operating cost.

\begin{tabular}{|c|c|c|c|c|}
\hline Base Vehicles & 773,073 & \multicolumn{3}{|c|}{\begin{tabular}{|l} 
Household Vehicle Distribution \\
\end{tabular}} \\
\hline Revised Vehicles & 724,147 & \begin{tabular}{|l|} 
Number of \\
Vehicles
\end{tabular} & $\begin{array}{l}\text { Original \% of } \\
\text { Households }\end{array}$ & $\begin{array}{l}\text { Revised \% of } \\
\text { Households }\end{array}$ \\
\hline Percent change in vehicles owned & $-6.33 \%$ & 0 & $6.4 \%$ & $10.3 \%$ \\
\hline Households & 454,976 & 1 & $39.4 \%$ & $40.3 \%$ \\
\hline Households Impacted & 48,926 & 2 & $39.5 \%$ & $35.9 \%$ \\
\hline$\%$ Households Impacted & $10.75 \%$ & 3 & $9.6 \%$ & $9.0 \%$ \\
\hline$\%$ Original Car Owning Households Impacte & $11.49 \%$ & 4 & $3.7 \%$ & $3.4 \%$ \\
\hline New transit trips & $18,025,671$ & $5+$ & $1.4 \%$ & $1.2 \%$ \\
\hline New annual transit trips/relinquished vehicle & 368 & & $100.0 \%$ & $100.0 \%$ \\
\hline Percent change in $\mathrm{HH}$ spending for vehicles & $-5.70 \%$ & & & \\
\hline Household savings per relenquished vehicle & $\$ 3,527$ & & & \\
\hline Base mean vehicle ownership per $\mathrm{HH}$ & 1.699 & & & \\
\hline Revised mean vehicle ownership per $\mathrm{HH}$ & 1.592 & & & \\
\hline
\end{tabular}

Figure 27 Household Vehicle Distribution with Reduced Mean Vehicle Ownership

The forecast produced a 138 percent increase in service and a 158 percent increase in ridership with a resultant increase in mode share of 1.08 percent (more than a doubling of the existing mode share). The most comparable basis for contrasting these two observed behaviors is shown in Table 8. 
Table 8 Comparison of Mode Change versus Auto Availability

\begin{tabular}{|l|c|c|}
\hline & 2006 Census ACS & 2001 NHTS derived \\
\hline Change in mean household auto ownership & -.1 & -.1 \\
\hline Change in commute mode share & $+.44 \%$ & \\
\hline Change in transit mode share (Scenario 3) & & $+1.08 \%$ \\
\hline Change in transit mode share (Scenario 4) & & +0.47 \\
\hline $\begin{array}{l}\text { Source: American Community Survey, Census 2006 and National Household Travel Survey, NHTS } 2001 \\
\text { derived }\end{array}$ \\
\hline
\end{tabular}

To evaluate the reasonableness of the travel behavior assumptions embedded in the NHTS household data on travel as a function of household vehicle ownership and adult population, we attempted to compare these results to the travel changes that different vehicle ownership levels would produce according to that ACS data on the observed differences in vehicle ownership and mode choice across metropolitan areas. These data, shown in Figure 10 in Chapter 3, can be regressed to produce an equation that shows an approximate 0.44 increase in the percent of commuters who use public transit for commuting for each decline in mean household auto ownership of 0.1 vehicles. In terms of elasticity of work trip commute mode share with respect to mean household vehicle availability the value is approximately -0.18 when working within the range of vehicle availability of 1.6 to 1.9 per household. This relationship is subsequently compared with NHTS derived travel behavior changes as a function of vehicle availability at the household level as shown in Table 7 .

This suggests that the household level data implies a greater sensitivity to mode share at least when the reductions in auto availability are spread relatively uniformly across household types and the number of zero-vehicle households increases significantly. This led to Scenario 4 where the change in vehicles was designed to not increase zero-vehicle households. This required approximately 20 percent of other households to relinquish a vehicle to produce the 0.1 decline in mean household auto ownership. It also significantly impacted the service and ridership response. Far fewer transit trips are generated due to households becoming zero-car households yet the relinquished vehicle savings is the same and the service supply afforded is comparable (not quite as high due to lower fare revenues). Service increased 137 percent and ridership increased 68 percent. 
This scenario much more closely matches vehicle availability and transit use relationships observed across metro areas in ACS data.

\subsection{Overall Observations and Conclusions}

Interest in exploring policies that collectively move toward greater transit use and lower auto dependency are logical in an era where we are faced with high transportation costs, congestion, environmental concerns, and affordable housing concerns. Both theoretical and empirical underpinnings established a relationship between transit use and vehicle ownership. It is logical to attempt to couple policy actions such that this relationship can be leveraged positively by providing enhanced transit service to enable and encourage reduced vehicle reliance by households.

In spite of this logical policy direction, research to back up policy planning is in relatively short supply and much of the research that has been carried out is somewhat superficial and is not necessarily founded on economically or behaviorally sound assumptions. While there is some information on how transit use has changed in response to vehicle availability, a lot less is known about the viability of initiatives to, in effect, reverse this process and produce greater transit use accompanying declining auto availability. This modest initiative provides some direction and observations on how that might be accomplished and how viable such policies might be.

This effort is the first we are aware of to look more closely at empirically derived household spending as a function of the number of vehicles in the household. Literature typically cites average costs, often for new vehicles, and implies this represents the potential savings from household vehicle reductions. In reality, the marginal cost per incremental household vehicle appears to be well below numbers frequently seen in the literature purporting to be average vehicle ownership cost. The realizable household savings from relinquishing vehicles is more correctly reflected by using the marginal vehicle ownership cost. While one does not know exactly how households would adapt in cases of declining auto ownership (if the household composition remained constant) incremental spending per incremental vehicle data from the consumer expenditure survey would appear to be a more accurate representation of the potential economic impacts on households from reducing vehicle ownership. Interestingly, zero-car households do have vehicle expenditures as might be 
expected as these households may be renting vehicles occasionally, maintaining their license, or paying for gas, tolls, or parking when they ride with others.

The consumer expenditure survey data indicate an average household savings of approximately $\$ 3,500$ would be realized for each reduced vehicle. In reality those households choosing to relinquish a vehicle may not be average. The actual mean savings varies significantly across household types and is actually highest in instances where households have more vehicles than adults. It is hypothesized that these households' incremental vehicle purchases involved discretionary specialized vehicles, perhaps a recreational vehicle, luxury sedan, or sports car, that represent more than just an investment in mobility. Depending upon the nature of the policy initiative, lower income households with very low auto ownership costs attributable to the fact that they perhaps own an older vehicle that is poorly maintained, under or not insured, and self maintained, may choose to relinquish a vehicle that produces a modest economic savings. Alternatively, higher income households with extra discretionary vehicles may relinquish a vehicle that produces significant economic savings but virtually no impact on travel behavior.

This research identifies the logical observation that the travel behavior consequences from vehicle reduction as well as the travel behavior adjustments required by households resulting from vehicle reduction would vary dramatically depending upon the existing vehicle supply situation in the household relative to the number of drivers. Households with surplus vehicles are more likely to be in a position where they are able to reduce vehicle ownership and less likely to be in a position where this change in household fleet would influence travel behavior. The travel behavior data suggest that there is a very significant difference in probable impact on transit use depending on which households relinquish vehicles. Huge shares of the transit increase associated with relinquishing vehicles can be attributed to households shifting from one to zero vehicles. Based on NHTS data, if there was a uniform reduction in vehicle ownership across household categories 88 percent of the increase in transit travel would be attributable to households moving to zero vehicle status. Clearly, existing travel behavior data indicate policies targeting vehicle reduction with the hope of increased transit use will require the creation of more zero-vehicle households or changes in behavior such that multi-adult households with vehicle shortages began shifting meaningful amounts of travel to public transportation - more so than is typically the case today for comparable households with different levels of vehicle availability. 
This research suggests that a significant share of the household vehicle ownership savings would need to be captured in some form to support the incremental cost of providing additional transit service even though only modest shares of diverted travel would be captured by public transportation. The average unit subsidy per public transit trip in the US, net of fares but inclusive of the cost of providing supportive capital, is such that it would be likely to require 50 percent or more of the household vehicle relinquishing savings in some manner redirected to support public transportation services. This actual relationship would be influenced highly by the extent to which vehicle relinquishing resulted in higher transit ridership of the type modeled in the scenarios that assumed uniform reductions in vehicle ownership across all ownership categories. On the other hand, if a vehicle reductions strategy resulted in vehicle relinquishing primarily for multi-vehicle households, they would create far lower additional transit demand and hence the necessary additional service could be supported by a far lower share of the relinquished vehicles savings being redirected to transit subsidy.

These scenario applications were applied across an urban area with relatively modest existing transit use. It should be recognized that the application context could vary dramatically from these basic conditions. Specific study areas or different areas might provide somewhat different results; however, the fundamental behaviors would not be expected to change dramatically. A targeted experiment on a specific geography with a specific vehicle reduction policy and specifically designed transit service expansion might provide greater opportunity to show efficiencies in transit service that might enable a more efficient operation requiring less new revenues.

This topic area would benefit from data revealing actual experiences with vehicle reduction initiatives and the subsequent consequence to transit use and household travel expenditure savings. While we have data on the historic trend of growing vehicle availability and declining transit use, we do not have data to understand how reversing these trends might impact behaviors. Follow-up travel behavior studies for those folks that have committed to a location efficient mortgage or who may have made a relocation decision that involved vehicle reductions and relocation to areas with much higher transit service, might provide a potential data source for understanding transit use changes. The underlying travel and transportation spending behaviors embedded in this analysis are aggregate and not specific 
to a context or experiment where specific programs were implemented. While we believe this analysis is both very reasonable and the best available with existing data, it is acknowledged that it remains speculative.

The spreadsheet tool developed as part of this research provides a very convenient mechanism for evaluating scenarios of vehicle reduction and assessing the financial and travel implications. The tool is easy to use and sufficiently transparent that an analyst could test a variety of scenarios, alter numerous assumptions or even the behavioral database to see what the implications are. The spreadsheet is readily available for anyone to use or modify should they be interested in exploring this issue in their context or for follow-up research.

Occasionally, policy analysts assume an ability to capture household savings associated with vehicle relinquishing and subsequently use these resources to support public transportation. The reality is that such an initiative would likely cause huge equity implications as vehicle reductions would be discreet integer decisions (e.g., one cannot decide to reduce vehicle ownership by 0.27 vehicles, for example) borne by those households that chose to reduce vehicles which in all probability would be a modest share of total households. Thus, these households would receive the economic benefits of relinquishing vehicles but it is unlikely that revenue raising mechanisms could be targeted to specifically capture revenues from those households nor would one expect the same vehicle ownership behavior changes to be realized if savings from giving up a vehicle were not accrued predominately to the household making that decision. Consequently, new revenue sources to support public transportation would most likely be applied far more uniformly across the entire population whether or not the individuals relinquished a vehicle or directly benefited from the expanded transit service. Thus, the ability to couple transit service expansion initiatives with policies to encourage vehicle ownership reductions might be more difficult than implied. There are clearly a host of mechanisms including pricing of vehicle ownership but extending well beyond that to include things like parking availability and urban design features that could ultimately be part of a policy initiative.

Service supply enhancements are unlikely to be sufficient in and of themselves to induce sufficient additional ridership to enable lower vehicle ownership levels based on the transit service elasticity that exists today and the cost structure for public transit that exists today. 
Empirical data on transit service elasticity implies that services would need to double or triple to induce enough additional riders that lower auto ownership might be anticipated based on the historical relationship between transit use and auto ownership. Unfortunately, the costs of funding the service expansion is likely to exceed the probable ability to capture new revenues based on the diversion of assumed households auto reduction savings alone. The catch lies in the fact that existing activity patterns are such that service expansion elasticities are well below one in many or most transit markets.

This research effort did not incorporate any sensitivity to travel time considerations that might influence the willingness of individuals to forgo vehicle ownership or change travel modes. A full benefit-cost analysis of policies to change vehicle ownership might include consideration of travel time changes for users of all modes and an assessment of the impact of an initiative on the performance of all modes.

In summary, we believe this area of research and policy consideration has merits. This work sheds additional light on the behaviors that would come into play in proposing initiatives for service expansion coupled with hoped-for or induced auto ownership reductions. The findings indicate that the transit impact of vehicle ownership reductions is currently highly dependent on increasing zero-vehicle households. Growing zero vehicle households would be expected to have a meaningful impact on transit use but this would also require a very significant additional investment in transit that is very significant in the context of the total households savings from vehicle relinquishing. Thus, the most promising initiatives are likely to be those that use a variety of incentives for transit use and disincentives for auto ownership/use in locations where transit service can be provided efficiently. 


\section{BIBLIOGRAPHY}

${ }^{1}$ National Alliance of Public Transportation Advocates. The Benefits of Public

Transportation. 2005. http://www.napta.net/advocacy_pubs_benefits.asp. Accessed April 11, 2007.

${ }^{2}$ Krizek, K. User Perspectives on Location Efficient Mortgages \& Car Sharing. Publication MN/RC - 2005-24. Minnesota Department of Transportation, 2005.

${ }^{3}$ Surface Transportation Policy Project and Center for Neighborhood Technology. Driven to Spend: Pumping Dollars out of Our Households and Communities, June 2005.

http://trb.org/news/blurb_detail.asp?id=5116. Accessed April 11, 2007.

${ }^{4}$ Institute for Location Efficiency. Introducing the Location Efficient Mortgage, 2002.

http://www.locationefficiency.com/publications/lem-brochure.pdf. Accessed April 11, 2007.

${ }^{5}$ Maat, K., and H.J.P. Timmermans. Household Car Ownership in Relation to Residential and Work Location. Paper presented at the Transportation Research Board 86th Annual Meeting, Washington DC, January 21 - 25, 2007, Paper No. 07-0220.

${ }^{6}$ Memmott, J. Trends in Personal Income and Passenger Vehicle Miles. Bureau of Transportation Statistics Special Report, SR-006, October 2007.

http://www.bts.gov/publications/bts_special_report/2007_10_03/html/entire.html, Accessed November 8, 2007.

${ }^{7}$ Ramjerdi, F., L, Rand, and I. Satermo. Models on Car Ownership, Transactions and Vehicle Type. www.tft.Ith.se/kfbkonf/5ramjerdiRandSetermo.PDF. Accessed April 11, 2007.

${ }^{8}$ Pucher, J. Urban Travel Behavior as the Outcome of Public Policy: The Example of Modal-Split in Western Europe and North America, Journal of the American Planning Association, Vol. 54, No. 4, 1988, pp.509-520.

${ }^{9}$ Newman, P., and J. Kenworthy. Gasoline Consumption and Cities. Journal of the American Planning Association, Vol. 55, No. 1, 1989, pp: 24-37.

10 Young J., and P.S. Hu. Summary of Travel Trends: 1990 National Personal Transportation Survey. Federal Highway Administration, Washington, D.C., March 1992.

${ }^{11}$ Barnes G., and P. Langworthy. The Per-mile Costs of Operating Automobiles and Trucks, State and Local Policy Program. Minnesota Department of Transportation, June 2003.

${ }^{12}$ Lipman, B.J. A Heavy Load: The Combined Housing and Transportation Burdens of Working Families. Center for Housing Policy, October 2006.

${ }^{13}$ U.K. Department of Transport. Transportation Statistics Bulletin, National Travel Survey: 2005, 2006.

http://www.dft.gov.uk/pgr/statistics/datatablespublications/personal/mainresults/nts20051/. Accessed April 11, 2007. 
${ }^{14}$ BLS Handbook of Methods, Chapter 16, Consumer Expenditures and Income, U.S. Department of Labor Bureau of Labor Statistics, http://www.bls.gov/opub/hom/pdf/homch16.pdf

${ }^{15}$ Victoria Transport Policy Institute. Transportation Costs \& Benefits; Resources for Measuring Transportation Costs and Benefits. http://www.vtpi.org/tdm/tdm66.htm. Accessed April 11, 2007.

${ }^{16}$ Bureau of Economic Analysis. Personal Income and Outlays. U.S. Department of Commerce, Washington, D.C., August 2007. http://www.bea.gov/newsreleases/national/pi/2007/pi0807.htm. Accessed October 13, 2007.

${ }^{17}$ American Automobile Association. Your Driving Costs 2007: How Much Are You Really Paying to Driver? http://www.aaanewsroom.net/Assets/Files/20075141456240.YourDrivingCosts2007.pdf Accessed May 2007.

${ }^{18}$ Bureau of Transportation Statistics, Transportation Statistics Annual Report, Table G-6. U.S Department of Transportation, Washington, D.C., 2006.

${ }^{19}$ Bureau of Transportation Statistics, Transportation Statistics Annual Report, Table 3-14. U.S Department of Transportation, Washington, D.C., 2006.

${ }^{20}$ Bureau of Transportation Statistics, Transportation Statistics Annual Report, Table G-3. U.S Department of Transportation, Washington, D.C., 2006.

${ }^{21}$ Edmunds.com. True Cost to Own.

http://www.edmunds.com/apps/cto/about.jsp\#depreciation. Accessed April 2007. 